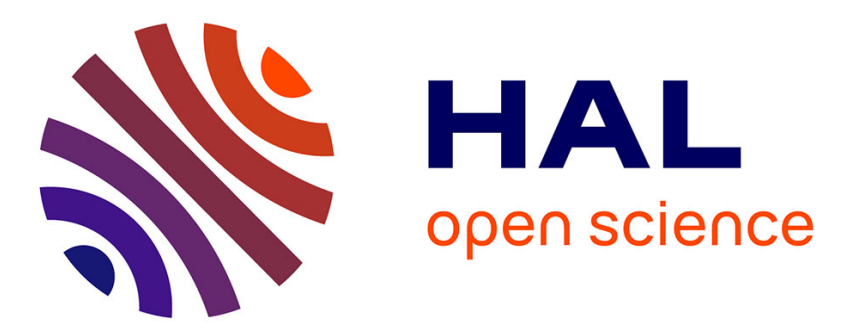

\title{
Energy-saving Technology Adoption under Uncertainty in the Residential Sector
}

Dorothée Charlier, Alejandro Mosino, Aude Pommeret

\section{To cite this version:}

Dorothée Charlier, Alejandro Mosino, Aude Pommeret. Energy-saving Technology Adoption under Uncertainty in the Residential Sector. Annales d'Economie et de Statistique, 2011, 103-104, pp.43-70. 10.2307/41615493 . hal-00937500

\section{HAL Id: hal-00937500 https://hal.science/hal-00937500}

Submitted on 28 Jan 2014

HAL is a multi-disciplinary open access archive for the deposit and dissemination of scientific research documents, whether they are published or not. The documents may come from teaching and research institutions in France or abroad, or from public or private research centers.
L'archive ouverte pluridisciplinaire HAL, est destinée au dépôt et à la diffusion de documents scientifiques de niveau recherche, publiés ou non, émanant des établissements d'enseignement et de recherche français ou étrangers, des laboratoires publics ou privés. 


\title{
Energy-saving technology adoption under uncertainty in the residential sector
}

\author{
Dorothée Charlier, Alejandro Mosiño and Aude Pommeret
}

October 5, 2009

\begin{abstract}
Home renovation is generally asserted to be a highly effective means for households to lower expenditures on energy. In this sense, home renovation can also be thought as a means to reduce GHG emissions. In this paper we consider a homeowner who makes an irreversible energy-efficiency investment in an uncertain environment. In a general equilibrium framework, we solve the program of a representative consumer who uses his wealth to invest in the energy-saving technology, to save or to consume energy goods and non-energy goods. Resolution is analytical in a zero discounting case and numerical for the general case, based on collocation and Chebychev polynomials. In particular, we show that the threshold triggering adoption depends not only on technological parameters but on preference parameters as well. Moreover, we show that uncertainty does not affect adoption in the same way as in a partial equilibrium framework.

JEL classification: Q55, D11, D81,C61

Keywords : energy-saving technology, uncertainty, optimal timing, residential sector.
\end{abstract}

\section{Introduction}

Reducing GHG emissions is nowadays becoming one of the priorities of policy makers in many developed countries. For instance, the French government wishes to reduce emissions by four by 2050 . Nevertheless, such a concern appears in a context of growing energy demand. This phenomenon is in part due to the importance of residential energy: in France, buildings account for $23 \%$ of $\mathrm{CO}_{2}$ emissions, of which $70 \%$ are generated by the residential sector, and for $46 \%$ of final energy consumption (ANAH, 2008). Energy demand in the residential sector depends mainly on the intensity of use of energy appliances and on their efficiency (see Hausman, 1979). Indeed, home renovations are generally asserted to be a highly effective means for households to lower expenditures on energy through increased efficiency and they become therefore a key target for environmental policies. For instance, enhanced insulation and energy-efficient ventilation of residential buildings are new technologies that can considerably 
reduce the energy consumption for indoor heating and cooling (Farsi, 2009). Cost-benefit analyses point to the economic viability of these systems even if the comfort co-benefits such as improvements in indoor air quality and protection against noise are not taken into account (Jakob, 2006, Ott et alii, 2006). However, actual investment in these systems is still relatively rare (Banfi et alii, 2008). This paper aims at carefully explaining the home renovation decision of households in a theoretical model. In particular, we explicitly take into account that such a decision takes place in an uncertain environment, in which there exist arbitrages between consumption, savings, and investment in home renovation.

The literature has already tried to explain the slow diffusion of energy efficient investments -the so-called "energy paradox" or "energy-efficiency gap" (Jaffe and Stavins, 1994a). Everything happens as if agents were discounting with unusually high rates to appraise energy-efficiency investment, ranging from $25 \%$ to $30 \%$ (see Brown 2001 and Sanstad et al. 1995). The usual suspect is the option value generated by the irreversibility of the investment decision in a stochastic environment that drives a wedge between the investment valuation and the Net Present Value. Hasset and Metcalf (1995) consider models in which households minimize the cost of energy expenditures subject to a given level of comfort (moreover, accommodations are heterogeneous in Hasset and Metcalf, 1993). Investment in renewable energy or in insulation is irreversible and future benefits are uncertain because of energy price fluctuations. Based on simulations of this model and energy price data, they obtain that the discount rate should be four times higher for energy-saving investments than for other kinds of investments. In Ansar and Sparks (2009), the potential investor may delay adoption not only because of the joint effect of irreversibility and uncertainty, but also to cash in on future experience-curve effects: with the passage of time, firms gain practical knowledge in producing and installing the energy-saving technology, enabling them to reduce the technology cost per unit of energy saved. Simulations for photovoltaic systems highlight the experience-curve effect as a fundamental reason for which households and firms delay making energy-saving investments until internal rates of return exceed values of $50 \%$, consistent with observations in the Economics literature.

Conversely, for Jaffe and Stavins (1994a,b) delaying energy-saving investment is costly. An example is the difference between incorporation of energy saving technology in a new home as opposed to an existing home. In the case of the new home, forgoing the technology at the time of construction typically means that the cost of installation later (if it is undertaken) will be higher. These investment decisions do not satisfy the assumptions of the option value model, but further development of the option value approach could overcome such shortcomings. Their conclusion is that there may simply be no way, using observations of purchase decisions alone and assuming optimizing behaviour, of disentangling the effects of consumer discounting, energy price expectations, and principal-agent problems, each of which could account for high implicit dis- 
count rates. Finally, some literature now turns to explanations such as behavioral and organisational barriers, leading to some bounded rationality (Sanstad and Howarth 1994, Boulanger, 2007, or Diaz-Rainey and Ashton, 2009).

In this paper we go back to the standard assumptions of irreversible energysaving technology adoption and of uncertain payoffs. Instead of relying on bounded rationality we focus on the characteristics of consumers that take the adoption decision in the residential sector. Existing literature considers partial equilibrium settings, and therefore ignores the interaction between optimal consumption and optimal adoption as well as the notions of risk aversion ${ }^{1}$ or intertemporal substitutions. To challenge these results, we reconsider the joint effect of irreversibility and uncertainty on the energy-efficiency investment decision in a general equilibrium framework. Theoretical analyses of technology adoption in general equilibrium and a stochastic environment are very recent and very limited in number. Hugonnier et al. (2008) study the optimal adoption of a new technology that increases the productivity of capital. ${ }^{2}$ There exists then an optimal adoption timing, and this timing is highly sensitive to the size of uncertainty as well as to the degree of agents' risk aversion. Moreover, Pommeret and Schubert (2009) tackle the specific problem of abatement technology adoption under uncertainty in a general equilibrium. The authors first determine the socially optimal adoption timing that is affected by the existence of pollution. Second, they derive the tax scheme such that in a decentralized economy firms adopt the abatement technology for the same level of economic development as in the centralized economy.

Tackling the specific problem of a homeowner who may invest in new insulation, or double glazing in order to reduce his energy bill is a bit different. The determination of the optimal investment timing is affected by the consumption of goods and services other than residential energy services (called "non-energy goods" in the rest of the paper). Therefore, we extend the general equilibrium model with a real option proposed by Hugonnier et al. (2008). We solve the program corresponding to the optimal adoption of an energy-saving technology adoption by a representative consumer who uses his wealth to save or to consume energy goods and non-energy goods. We assume that the benefits of such energy-saving technologies are uncertain due to the lack of information about them. ${ }^{3}$ The financial return on savings is assumed to be stochastic as well. Because of uncertainty, we obtain that it may be optimal to reduce both consumptions in order to foster adoption. As usual (see Hugonnier et al., 2008, or Pommeret and Schubert, 2009) the model can only be solved analytically if the utility discount factor is zero. Nevertheless, we confirm our results in

\footnotetext{
${ }^{1}$ See Farsi (2009) for the role of risk aversion in the energy efficient investment decision based on an empirical approach.

${ }^{2}$ This paper, together with Hugonnier et al. (2005), provides the resolution for the optimal threshold that triggers an irreversible decision in a general equilibrium framework for the first time in the literature.

${ }^{3}$ Another interpretation for this uncertainty (that do not perfectly fit our modelling) would come from the great fluctuations in energy prices.
} 
the more general case with non-zero discounting using a numerical procedure based on collocation and Chebychev polynomials. We show that the threshold triggering adoption depends not only on technological parameters but on preference parameters as well. In particular, the higher the risk aversion parameter, the smaller the level of wealth which is required for adoption. Finally, we also show that while uncertainty on energy-saving technologies efficiency hardly affects adoption timing, uncertainty on financial returns fosters it. The latter result is strikingly different from what is obtained in partial equilibrium. As a consequence, it stresses that the existence of an option value is not sufficient to explain the "energy paradox", as suggested by Sanstad, Blumstein \& Stoft (1995).

The remainder of the paper is as follows. Section 2 presents the general model, and explains the assumptions that will be valid for the whole paper. Because this model is to be solved backwards, we start in section 3 by developing the general equilibrium framework once the energy-efficient technology has been adopted. In Section 4 we analytically solve the model before the technology adoption and derive the optimal adoption timing in the special case of zero discounting. We provide also some sensitivity analysis based on numerical resolutions. We confirm these results in section 5 with the more general case of a strictly positive discount rate. Section 6 concludes.

\section{The model}

We assume that the homeowner holds risky assets. His income return encompasses a deterministic part, $r$, and a stochastic one, $\sigma_{2} d z_{2}$. He consumes energy goods $C_{2}$ and non-energy goods $C_{1}$. The function of wealth accumulation consists of two components. The deterministic one is $r A_{t}-C_{1 t}-x C_{2 t}$, with $A_{t}$ the level of wealth and $x$, the relative price of energy. The stochastic component comes from the stochastic financial returns. The function of wealth accumulation writes therefore:

$$
d A=\left(r A-C_{1}-x C_{2}\right) d t+\sigma_{2} A d z_{2 t} \text { for } t<\tau
$$

At any time $\tau$, the household can lower the cost $x$ of the energy service by switching to a new technology $y$. The initial cost of the new technology is $\beta$. This cost is unrecoverable. Moreover, there exists an uncertainty $\sigma_{1}$ that is linked to the cost of consumption in energy service after the adoption of the new technology. Indeed, we assume that the benefits of such energy-saving technologies are uncertain due to the lack of information about them. Note that $y$ must be less than $x$ because the cost of the energy service is otherwise higher with the new technology and the homeowner never adopts. We define the difference between $x$ and $y$ as the savings in energy efficiency. The function of wealth accumulation after the adoption of the new technology is:

$$
d A=\left(r A-C_{1}-y C_{2}\right) d t-\sigma_{1} y C_{2} d z_{1 t}+\sigma_{2} A d z_{2 t} \text { for } t \geq \tau
$$


The homeowner preferences over consumption plans are represented by the lifetime expected utility functional

$$
E_{0}\left[\int_{0}^{\infty} e^{-\rho t} U\left(C_{1 t}, C_{2 t}\right) d t\right]=E_{0}\left[\int_{0}^{\infty} e^{-\rho t} \frac{\left(C_{1}^{a} C_{2}^{b}\right)^{1-\gamma}}{1-\gamma} d t\right]
$$

To facilitate the presentation, let denote $\Theta$ the set of admissible plans, that is, the set of consumption plans and dates of adoption $(C, \tau)$ such that

$$
E_{0}\left[\int_{0}^{\infty} e^{-\rho t} U\left(C_{1 t}, C_{2 t}\right) d t\right]<\infty
$$

where $\rho$ is the consumer subjective discount factor, $\gamma$ is the constant relative risk aversion of the household with $\gamma \neq 1$ and $\gamma>0$. The elasticities $a$ and $b$ are positives. We define the effective coefficient of risk aversion (see Smith and Son, 2005):

$$
R=1-(a+b)(1-\gamma)
$$

The optimal switching time should maximize the intertemporal utility subject to the function of wealth accumulation, the non-negativity constraint and the initial condition $A_{0}$. The value function of the homeowner is :

$$
V\left(A_{0}\right)=\sup _{(C, \tau)} E_{0}\left[\int_{0}^{\tau} e^{-\rho t} \frac{\left(C_{1 t}^{a} C_{2 t}^{b}\right)^{1-\gamma}}{1-\gamma} d t+e^{-\rho \tau} W\left(A_{\tau}-\beta\right)\right]
$$

where $W$ is the value after having adopted the new technology and $\tau$ is the optimal adoption time.

This program can be solved in two stages. First, we solve for the optimal consumption plans of the representative agent after the adoption of the new technology. Then, there is no longer an adoption option in the value of the program. We find the expression of the value function which provides the boundary condition to compute the equilibrium of our general model with a technology adoption opportunity. Note that it also provides a benchmark for the economy with the technology adoption option. Second, we formulate the choice of an optimal consumption plan and an optimal investment time prior to technology adoption.

\section{The optimal path after adoption}

We assume in this section that the new technology has been adopted. The set of admissible plans collapses to the set of consumption plans such that :

$$
E_{\tau}\left[\int_{\tau}^{\infty} e^{-\rho(t-\tau)}\left|U\left(C_{1 t}, C_{2 t}\right)\right| d t\right]<\infty
$$

The value function of the household is :

$$
W\left(A_{\tau}\right)=\sup _{C} E_{\tau}\left[\int_{\tau}^{\infty} e^{-\rho(t-\tau)} \frac{\left(C_{1 t}^{a} C_{2 t}^{b}\right)^{1-\gamma}}{1-\gamma} d t\right]
$$


The Bellman equation may be written :

$$
W\left(A_{t}\right)=\max _{C_{1 t}, C_{2 t}}\left\{\frac{\left(C_{1 t}^{a} C_{2 t}^{b}\right)^{1-\gamma}}{1-\gamma} d t+e^{-\rho d t} E_{t}\left(W\left(A_{t+d t}\right)\right)\right\} \text { with } t \geq \tau
$$

The first order conditions yield the optimal consumption of energy and nonenergy goods: ${ }^{4}$

$$
\begin{gathered}
C_{1 t}^{*}=\left[\frac{(a+b)}{a} M B^{-b(1-\gamma)}\right]^{\frac{1}{a(1-\gamma)-1}} A_{t} \\
C_{2 t}^{*}=B A_{t}
\end{gathered}
$$

We note that the optimal consumptions are both constant fractions of the wealth level with:

$$
\begin{gathered}
B=\frac{R y \pm(1-\gamma) \sqrt{\Delta}}{R \sigma_{1}^{2} y^{2}[2 R-b(1-\gamma)]}, \text { and } \\
\Delta=\left[y\left(a+b-\frac{1}{1-\gamma}\right)\right]^{2}-4\left[\frac{R}{2} \sigma_{1}^{2} y^{2}\left(2 a+b-\frac{2}{(1-\gamma)}\right)\right]\left[b \frac{R}{2} \sigma_{2}^{2}-b r+\frac{b \rho}{1-R}\right]
\end{gathered}
$$

The feasibility condition imposes $B>0$. Depending on the value of $\gamma$ relative to unity we consider one or the other root of the second order equation. Moreover

$$
M=\frac{a}{a+b} B^{-R}\left[\frac{a}{b}\left(y+R \sigma_{1}^{2} y^{2} B\right)\right]^{[a(1-\gamma)-1]}
$$

The expected optimal wealth growth rate is:

$$
\begin{aligned}
\frac{E_{t}\left(d A_{t} / A_{t}\right)}{d t} & =r-E_{t}\left[\frac{C_{1}^{*}}{A_{t}}\right]-y E_{t}\left[\frac{C_{2}^{*}}{A_{t}}\right] \\
& =r-\left[\frac{M}{a}(a+b) B^{-b(1-\gamma)}\right]^{\frac{1}{a(1-\gamma)-1}}-B y
\end{aligned}
$$

Note that this is a more complex expression than usual (see for instance Smith and Son, 2005) since consumption expenditure is itself directly affected by uncertainty in the wealth accumulation equation. The following results can be obtained analytically:

$$
\begin{gathered}
\frac{\partial\left(C_{1 t} / K_{t}\right)}{\partial \sigma_{2}^{2}}=\left[\frac{\partial\left(C_{1 t} / K_{t}\right)}{\partial M} \frac{\partial M}{\partial B}+\left.\frac{\partial\left(C_{1 t} / K_{t}\right)}{\partial B}\right|_{M=\bar{M}}\right] \frac{\partial B}{\partial \Delta} \frac{\partial \Delta}{\partial \sigma_{2}^{2}} \begin{array}{l}
>0 \text { for } \gamma<1 \\
\text { indeterminate for } \gamma>1
\end{array} \\
\frac{\partial\left(C_{2 t} / K_{t}\right)}{\partial \sigma_{2}^{2}}=\frac{\partial B}{\partial \Delta} \frac{\partial \Delta}{\partial \sigma_{2}^{2}}>0 \text { for } \gamma<1 \\
<0 \text { for } \gamma>1
\end{gathered}
$$

An increase in the uncertainty on the financial returns increases current consumption in both energy and non-energy consumption if the intertemporal elasticity of substitution $(1 / \gamma)$ is greater than unity. Moreover, current consumption

\footnotetext{
${ }^{4}$ See Appendix A.
} 
in energy goods decreases when uncertainty $\sigma_{2}$ rises if the intertemporal elasticity of substitution is less than unity. These results are consistent with the usual income and substitution effects: more uncertainty reduces the certainty equivalent of the financial returns which in turn generates an income effect (less current consumption) and a substitution effect (more current consumption). The substitution effect prevails if the intertemporal elasticity of substitution is large enough. Effects of $\sigma_{2}^{2}$ on $C_{1 t}$ for $\gamma>1$, or of $\sigma_{1}^{2}$ on both $C_{1 t}$ and $C_{2 t}$ are analytically indeterminate. Figures providing a numerical computation of these effects can be found at the end of appendix (A).

Finally, the explicit expression of the value function is:

$$
W\left(A_{t}\right)=W\left(A_{t}\right)=\frac{M A_{t}^{1-R}}{(1-\gamma)}
$$

It is easy to show that the condition on parameters such that the utility function is concave is $(a+b)(1-\gamma)-1<0$. The transversality condition requires the convergence of the value function, i.e.

$$
\lim _{t \rightarrow \infty} E_{0}\left(W\left(A_{t}\right)\right)=0
$$

It is satisfied if the lifetime utility of wealth does not grow "too fast" in expectation (see Smith (1996)). Applying Itô's lemma to $W\left(K_{t}\right)$, this requires that:

$$
\begin{aligned}
E(d A) & =W_{A} E(d A)+\frac{1}{2} W_{A A} E\left(d A^{2}\right)<0 \\
& \Leftrightarrow M\left[r-\left(\frac{M}{a}(a+b) B^{-b(1-\gamma)}\right)^{\frac{1}{a(1-\gamma)-1}}-x B-\frac{R}{2}\left(\sigma_{1}^{2} x^{2} B^{2}+\sigma_{2}^{2}\right)\right]>0,
\end{aligned}
$$

We assume that this condition is fulfilled.

\section{The optimal adoption timing with no discount- ing}

Considering the analytical resolution helps understanding the mechanisms of the model. However, solving analytically is only possible in the special case in which the consumer's discount rate is equal to zero ${ }^{5}$. This is why we assume zero-discounting in this section. Note that the expressions of the optimal consumption path and of the value function after the switch that have been derived in the previous section remain valid but we now impose $\rho=0$ in these expressions. Nevertheless, assuming that the consumer does not discount the future is not very realistic. Therefore, we will turn to numerical resolutions in the next section to show that introducing a discount factor does not change the nature of the results.

\footnotetext{
${ }^{5}$ See next section.
} 
Recall that the homeowner has to choose both an optimal consumption plan and an optimal technology adoption timing. This choice is given by the maximization of the intertemporal utility function subject to the wealth accumulation equation. Once the new technology has been adopted, the homeowner optimally follows the consumption plan described by equations (10) and (11). Therefore, the value function at the time of adoption is given by the following value matching and smooth pasting conditions :

$$
\begin{gathered}
V\left(A_{\tau}\right)=W\left(A_{\tau}-\beta\right) \\
V_{A}\left(A_{\tau}\right)=W_{A}\left(A_{\tau}-\beta\right)
\end{gathered}
$$

where $A_{\tau}$ is the level of wealth for which is optimal to adopt. It implicitly determines the optimal switching time $\tau$. The value matching condition (13) simply requires that, at the time of the switch (i.e for a level $A_{\tau}$ of wealth), the value before the switch is equal to the value after the switch once paid the initial costs. The smooth pasting condition (14) ensures the smoothness of the value function around the switch ( $V$ before the switch and $W$ after the switch). It guarantees that adoption occurs for the optimal level of wealth.

Since it is always possible for the homeowner to indefinitely postpone the adoption of the new technology, another condition has to be satisfied, namely that for any level of wealth, the value with the adoption opportunity $V$ cannot be smaller than $W_{0}$, the value without such an opportunity:

$$
W_{0}\left(A_{t}\right) \leq V\left(A_{t}\right) \quad \forall t
$$

The household's program is :

$$
\begin{aligned}
V\left(A_{0}\right) & =\sup _{C, \tau} E_{0}\left[\int_{0}^{\tau} \frac{\left(C_{1 t}^{a} C_{2 t}^{b}\right)^{1-\gamma}}{1-\gamma} d t+W\left(A_{\tau}-\beta\right)_{\{\tau<\infty\}}\right] \\
\text { s.t. } d A & =\left(r A-C_{1}-x C_{2}\right) d t+\sigma_{2} A d z_{2 t}
\end{aligned}
$$

To solve the program before the switch, we determine the marginal value of wealth which has to satisfy the smooth pasting condition. Integrating this value between zero and the level of wealth at the optimal switching time, we can use the value matching condition to get the optimal adoption date.

\subsection{The marginal value of wealth}

The first order condition yields: ${ }^{6}$

$$
\begin{aligned}
C_{1 t}^{*} & =a^{\frac{1-b(1-\gamma)}{R}}\left(\frac{b}{x}\right)^{\frac{b(1-\gamma)}{R}} V_{A}^{-\frac{1}{R}} \\
C_{2 t}^{*} & =a^{\frac{a(1-\gamma)}{R}}\left(\frac{b}{x}\right)^{\frac{1-a(1-\gamma)}{R}} V_{A}^{-\frac{1}{R}}
\end{aligned}
$$

\footnotetext{
${ }^{6}$ See appendix B.
} 
Using a variable change, the Bellman equation leads to the following expression for the marginal value of wealth before the switch (see Appendix B) :

$$
\begin{aligned}
V_{A}\left(A_{t}\right) & =[D_{1} A_{t}^{-1}+\underbrace{D_{2} A_{t}^{D_{3}}}_{G(t)}]^{R} \\
\text { with } D_{1} & =\left[\frac{R}{\gamma-1} a^{\frac{a(1-\gamma)}{R}}\left(\frac{b}{x}\right)^{\frac{b(1-\gamma)}{R}}\right] \frac{1}{\left(r-\frac{1}{2} \sigma_{2}^{2} R\right)} \\
\text { and } D_{3} & =-\frac{2 r}{R \sigma_{2}^{2}}
\end{aligned}
$$

We note $G(t)=D_{2} A_{t}^{-\frac{r}{\frac{1}{2} R \sigma_{2}^{2}}}$ the option value to switch ${ }^{7} . D_{2}$ is a constant which must be determined ${ }^{8}$ using the smooth pasting condition (14). We obtain :

$$
D_{2}=\frac{[M(a+b)]^{\frac{1}{R}}}{\left(A_{\tau}-\beta\right) A_{\tau}^{D_{3}}}-\frac{D_{1}}{A_{\tau}^{D_{3}+1}}
$$

If the homeowner does not have the opportunity to adopt a new technology, there is no option value to adopt the new technology, $G(t)=0$, and the value function reduces to: ${ }^{9}$

$$
\begin{aligned}
W_{0}\left(A_{t}\right) & \left.=[\underbrace{\frac{R}{\gamma-1} a^{\frac{a(1-\gamma)}{R}}\left(\frac{b}{x}\right)^{\frac{b(1-\gamma)}{R}}}_{D_{1}}]^{R} \frac{A_{t}^{1-R}}{\left(a+\frac{1}{2} \sigma_{2}^{2} R\right)}\right]^{(1-\gamma)} \\
& \Leftrightarrow W_{0}\left(A_{t}\right)=\frac{D_{1}^{R}}{(a+b)} \frac{A_{t}^{1-R}}{(1-\gamma)}
\end{aligned}
$$

where $W_{0}\left(A_{t}\right)$ is the value function of the homeowner with no opportunity to switch. Moreover, the feasibility condition associated with the program in the absence of adoption opportunity writes:

$$
D_{1}>0
$$

Recall that $W_{0}\left(A_{t}\right)$ cannot be greater than the lifetime utility of the agent in an economy with the new technology; therefore we must have:

$$
W_{0}\left(A_{t}\right) \leq W\left(A_{t}\right)
$$

\footnotetext{
${ }^{7}$ Recall that under uncertainty, it is possible to delay an irreversible investment. While the homeowner is waiting, he can take advantage of an opportunity to invest, similar to what happens with a financial option. Therefore, there exists an option value of the investment project that is killed at the time of investment (see Dixit and Pindyck, 1994). This option value represents an opportunity cost of investment that must be taken into account.

${ }^{8}$ See appendix B.

${ }^{9}$ See appendix B.
} 
This condition ensures that there exists an optimal switching date, that is, in the absence of costs of switching to the new technology, the central planner would choose to immediately switch for any current level of wealth accumulation.

Using the expressions for $W_{0 A}$ (computed using equation (24)) and for $W_{A}$ (computed using equation (12)), the marginal value $V_{A}\left(A_{t}\right)$ can be rewritten:

$$
V_{A}\left(A_{t}\right)=[W_{0 A}\left(A_{t}\right)^{\frac{1}{R}}+\underbrace{\left(\left[W_{A}\left(A_{\tau}-\beta\right)\right]^{\frac{1}{R}}-W_{0 A}\left(A_{\tau}\right)^{\frac{1}{R}}\right) \frac{A \tau}{A_{t} \frac{2 r}{R \sigma_{2}^{2}}}}_{=G(t), \text { part due to the option to switch }}]^{R}
$$

The marginal value of wealth differs significantly from the one that can be derived in the absence of technological change. This is due to the existence of an option to switch that generates an option value taken into account in the marginal value of wealth. In the absence of such an option, $G(t)=0$ and the marginal value of wealth reduces to $W_{0 A}\left(A_{t}\right)$. This option value is the difference between the marginal value after the switch (having paid initial cost $\beta$ ) and the marginal value in the absence of opportunity to switch, discounted by the distance to the switch, that is related to the ratio between the current wealth $A_{t}$ and $A \tau$.

We have two cases :

- If $\gamma<1$, we have: $W_{0 A}\left(A_{t}\right)^{\frac{1}{R}}<W_{A}\left(A_{t}\right)^{\frac{1}{R}}<W_{A}\left(A_{t}-\beta\right)^{\frac{1}{R}}$ that ensures that $G(t)>0$. There is no problem of existence of $V_{A}$ in this case. The marginal value of wealth in the economy with an opportunity to switch is greater than the marginal value of wealth in an economy without this opportunity. It means that consumption at each time is smaller in an economy with opportunity to adopt a new technology, compared to the consumption which prevails in an economy in which the opportunity does not exist.

- If $\gamma>1$, we have $W_{0 A}\left(A_{t}\right)^{\frac{1}{R}}>W_{A}\left(A_{t}\right)^{\frac{1}{R}}$. In this case, the sign of $G(t)$ is ambiguous.

$-G(t)<0$. It means that the part due to the option to adopt a new technology in the expression of the marginal value of wealth is negative. Therefore, consumption at each period is greater in an economy with an opportunity to switch compared to the consumption which prevails in an economy without such an opportunity. In this case, the homeowner does not like to substitute and the option to adopt a new technology is an incentive to rise his consumption today to smooth his consumption path that is expected to grow more 
once the technology is adopted. Thus, adoption is delayed. However such a consumption path cannot happen since for small values of $A_{t}$, namely for $A_{t}<\left(-D_{1} / D_{2}\right)^{1 /\left(1-2 r / R \sigma_{2}\right)}$, the expression of $V_{A}^{\frac{1}{R}}$ becomes negative and the program is no longer defined. Therefore, $G(t)<0$ cannot be considered.

- $G(t)>0$. It implies that when integrating $V_{A}$, the following condition $W_{0}\left(A_{t}\right) \leq V\left(A_{t}\right) \quad \forall t \quad$ can no longer be satisfied (since for $\gamma>1$, feasibility condition implies $\left.2 r /\left(\sigma_{2}^{2} R\right)>1\right)$. Therefore, $G(t)>0$ cannot be considered.

$-G(t)=0$. It ensures both that $V_{A}^{\frac{1}{R}}$ is positive (the program is defined) and that the condition $W_{0}\left(A_{t}\right) \leq V\left(A_{t}\right) \quad \forall t$ is satisfied. It is the sole solution that we can consider if $\gamma>1$. It involves that the consumption is not affected by the existence of an option to adopt a new technology. We denote $A^{*}$ the special value of $A_{t}$ such that $G(t)=0$.

Therefore, we obtain using equation (24) and (26):

$$
A^{*}=\frac{\beta}{1-\frac{[M(a+b)]^{\frac{1}{R}}}{D_{1}}}
$$

$A^{*}$ must be positive, which requires $M(a+b)<D_{1}^{R}$ that is ensured by condition (25). Obviously, this threshold raises with the cost to pay for adoption and decreases with the savings in energy efficiency (see numerical resolutions in appendix B). The better the new technology compared to the old one, the smaller the threshold.

\subsection{Boundary conditions}

The level of wealth $A_{\tau}$ is such that, at the time to the adoption, the value with the initial technology is equal to the value with the new technology once the $\operatorname{cost} \beta$ is paid (this is the value matching condition):

$$
V\left(A_{\tau}\right)=W\left(A_{\tau}-\beta\right)
$$

Thus, we have again two cases :

- If $\gamma<1$, the threshold $A_{\tau}$ has to satisfy :

$$
\int_{0}^{A_{\tau}} V_{A}(A) d A=W\left(A_{\tau}-\beta\right)
$$

since $V(0)=0$ for $\gamma<1$. Note that $V_{A}$ is itself a function of $A_{\tau}$ through $D_{2}$. Equation (29) can be solved numerically. Simulations are driven using the following values for the parameters: $\sigma_{1}=0.013 ; b=0.25 ; a=0.7$; $\gamma=0.5 ; x=10 ; y=0.25 ; r=0.05 ; \sigma_{2}=0.5 ; \beta=0.1$. The value of the effective coefficient of risk aversion is $R=0.525$. 
Figure 1 shows the three value functions: $V(A)$ before the switch, $W(A-\beta)$ after the switch, and $W_{0}(A)$ without the option to switch. The threshold that triggers the switch is $A_{\tau}=0.82$. Note that at the time of adoption, $y C_{2}$ (with $C_{2}$ computed after adoption) is smaller that $x C_{2}$ (with $C_{2}$ computed before adoption). It implies that, at least at the time of adoption, the rebound effect does not prevail on energy consumption.

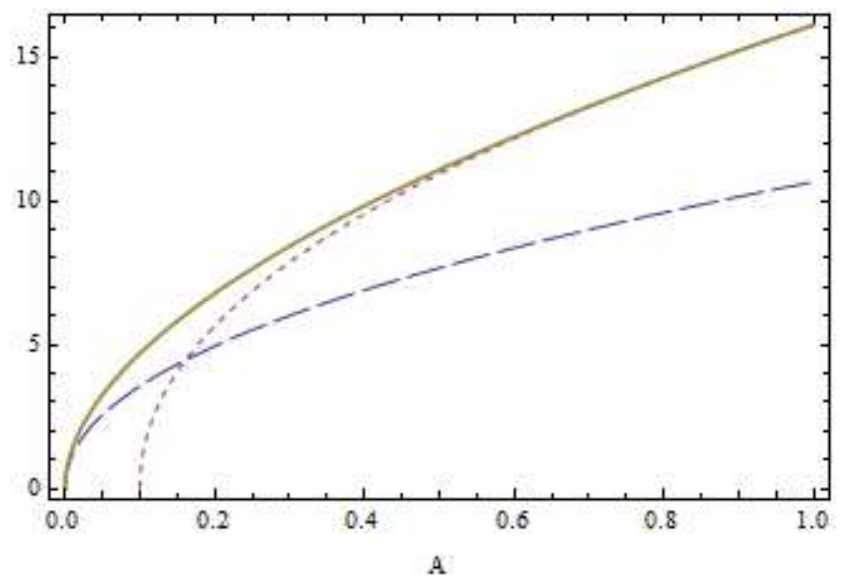

Thick line : $V(A)$

Small dashes : $W(A-\beta)$

Large dashes : $W_{0}(A)$

Figure 1: The value functions for $\gamma<1$ (optimum)

- If $\gamma>1$, we have that $A_{\tau}=A^{*}$ with $A^{*}$ given by equation (27). The boundary condition (13) allows to derive the value of the program before the switch :

$$
V\left(A_{t}\right)=\frac{1}{1-R}\left[D_{1}^{R} A_{t}^{1-R}+[M(a+b)]\left(A_{\tau}-\beta\right)^{1-R}-D_{1}^{R} A_{\tau}^{1-R}\right]
$$

Note that both $A^{*}$ and $V\left(A_{t}\right)$ are analytically defined with $\gamma>1$. Simulations to draw the value functions are driven using the following values for the parameters : $\sigma_{1}=0.013 ; b=0.25 ; a=0.7 ; \gamma=2 ; x=10 ; y=0.25$; $r=0.05 ; \sigma_{2}=0.1 ; \beta=0.1$. The value of the effective coefficient of risk aversion is $R=1.95$. 
Figure 2 shows the three value functions: $V(A)$ before the switch, $W(A-\beta)$ after the switch, and $W_{0}(A)$ without the option to switch. The threshold which triggers the switch is $A^{*}=0.265$ (see equation (27)). Contrary to what happens for $\gamma<1$, one may compute that the rebound effect prevails at the time of adoption.

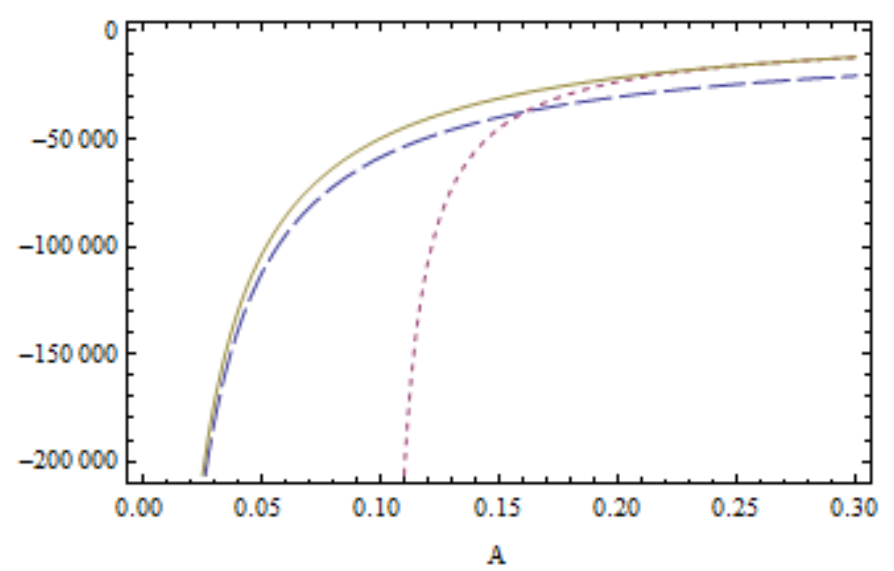

Thick line : $V(A)$

Small dashes : $W(A-\beta)$

Large dashes : $W_{0}(A)$

Figure 2: The value functions for $\gamma>1$ (optimum)

\subsection{Comparative statics}

We provide some figures in appendix $(\mathrm{C})$ to show the effect of each parameters. Parameters' values used to draw the value functions previously are now considered as baseline parameters for the simulations.

The level of wealth for which it is optimal to switch is a decreasing function of $x$ and an increasing function of $y$. It is quite intuitive that the larger the gain of adoption, the sooner the homeowner wishes to adopt and therefore the lower the level of wealth for which he wishes to adopt. Of course, we obtain that the higher the adoption cost, the higher the threshold wealth and the later the adoption.

Let us consider the effects of preference parameters. As far as parameters $a$ (on non-energy goods $C_{1}$ ) and $b$ (on energy goods $\left.C_{2}\right)^{10}$ are concerned, we obtain

\footnotetext{
${ }^{10}$ Note that we only present the results for values of $b$ between 0.2 and 0.4 because $b$ cannot be greater than $a$.
} 
the following results: the more sensitive the utility of the household to nonenergy consumption (i.e. the higher $a$ ), the later the homeowner wants to devote resources to adoption and then, the higher the optimal adoption threshold, but the effect of $b$ depends on the value of $\gamma$ relative to unity. The relative risk aversion coefficient $\gamma$ has a complex effect because it summarizes both the attitude with respect to risk and that with respect to intertemporal substitution. Simulations show that the higher $\gamma$, the smaller the level of wealth that triggers adoption.

Let us now turn to the effect of uncertainties. The level of wealth for which it is optimal to switch is not sensitive to the uncertainty $\left(\sigma_{1}\right)$ related to the efficiency of consumption in energy service after the adoption of the new technology. It is an increasing function of the deterministic part of financial return $(r)$ while it is a decreasing function of the uncertainty on the financial returns $\left(\sigma_{2}\right)$. First, the larger the deterministic return on wealth, the more reluctant the homeowner is to devote part of his wealth to technology adoption. Second, $\sigma_{2}$ reduces the certainty equivalent of the wealth rate of return $\left(r-\frac{1}{2} \sigma_{2}^{2} R\right)$ and it is no surprise that it affects adoption in the opposite way compared to $r$. These effects of $r$ and $\sigma_{2}$ only appear for $\gamma<1$. For $\gamma>1$ adoption becomes insensitive to these parameters.

\section{The optimal adoption time with discounting}

It is not possible to go on with the analytical resolution if the consumer discount rate is not equal to zero. Indeed, the Bellman equation before the switch is:

$$
\rho V=\max _{C_{1 t}, C_{2 t}}\left\{\frac{\left(C_{1 t}^{a} C_{2 t}^{b}\right)^{1-\gamma}}{1-\gamma}+V_{A}\left(r A-C_{1}-x C_{2}\right)+\frac{1}{2} \sigma_{2}^{2} A^{2} V_{A A}\right\}
$$

Maximizing wit respect to both $C_{1 t}$ and $C_{2 t}$ leads to

$$
\rho V \cdot V_{A}^{\frac{1-R}{R}}=\frac{R}{1-\gamma} a^{\frac{a(1-\gamma)}{R}} \frac{b}{x}^{\frac{b(1-\gamma)}{R}}+r A V_{A}^{\frac{1}{R}}+\frac{1}{2} \sigma_{2}^{2} A^{2} V_{A}^{\frac{1-R}{R}} V_{A A}
$$

Such an equation can no longer be solved using the variable change proposed in appendix B for $\rho=0$. As this Bellman equation cannot be solved analytically, we turn to a numerical resolution. More precisely, we adapt Judd's metodology (see Judd, 1992) based on Chebyshev polynomials and projection methods as proposed in Dangl and Wirl (2004).

\subsection{An approximate value function before adoption}

Using equation (32), let us define $L$ :

$$
L(V)(A)=\frac{R}{1-\gamma} a^{\frac{a(1-\gamma)}{R}} \frac{b}{x}^{\frac{b(1-\gamma)}{R}}+r A V_{A}^{\frac{1}{R}}+\frac{1}{2} \sigma_{2}^{2} A^{2} V_{A}^{\frac{1-R}{R}} V_{A A}-\rho V_{A}^{\frac{1-r}{R}} V .
$$


$L$ is an operator, or a function that maps functions to functions, and $A \in\left[0, A_{\tau}\right]$. As noted in Judd $(1992,1998)$, the domain of $L$ includes all the $C^{1}$ functions, and its range is $C^{0}$. The differential equation (32), combined with the value matching and smooth pasting conditions, equations (13) and (14) respectively, can be viewed as the problem of finding a $C^{1}$ function $V$ such that:

$$
\begin{aligned}
L(V)(A) & =0 \\
V\left(A_{\tau}\right) & =W\left(A_{\tau}-\beta\right) \\
V^{\prime}\left(A_{\tau}\right) & =W^{\prime}\left(A_{\tau}-\beta\right) .
\end{aligned}
$$

The projection method simplifies the original problem (33) by approximating the function $V(A)$ by means of polynomials. ${ }^{11}$ As we decided to use Chebyshev polynomials, our approximation can be written as:

$$
\widehat{V}(A, \mathbf{c})=\frac{1}{2} c_{0} T_{0}(A)+\sum_{i=1}^{N} c_{i} T_{i}(A),
$$

where $A \in\left[0, A_{\tau}\right]$, and $T_{i}(A)$ is the general $i$ th Chebyshev polynomial of the first kind that is defined by the following recurrence relationship:

$$
\begin{aligned}
T_{0} & =1 \\
T_{1} & =A \\
T_{n+1} & =2 A T_{n}(A)-T_{n-1}(A),
\end{aligned}
$$

or by the trigonometric identity:

$$
T_{n}(A)=\cos (n \arccos A) .
$$

Written in this way, the quality of our approximation is guaranteed by the Chebyshev approximation theorem (see Judd, 1992).

\subsection{Choosing the coefficients}

We need to choose $c=\left\{c_{0}, c_{1}, c_{2}, \ldots, c_{N}\right\}$ so that $\widehat{V}(A, c)$ nearly solves the differential equation (32). To do this, we first ignore the conditions (34) and (35), and define the residual function:

$$
R F(A, \mathbf{c}) \equiv L(\widehat{V})(A) .
$$

Equation (37) is the deviation of $L(\widehat{V})(A)$ with respect to the zero target value. The projection method adjusts the set of coefficients until a set $c$ is found that makes $R F(A, c)$ sufficiently close to the zero function. Equation (36) has then to be inserted into equation (37). Note that we have $N+1$ coefficients $c_{i}$ to be

\footnotetext{
${ }^{11}$ By Weierstrass theorem, we know that any $C^{1}$ function can be properly approximated by a large sums of polynomial terms. So, as $N$ becomes larger in our equation (36), we are sure that $\widehat{V}(A, c)$ is converging to $V(A)$.
} 
found. Therefore, we choose $N+1$ collocation values $A_{i} \in\left[0, \widehat{A}_{\tau}\right]$, where $\widehat{A}_{\tau}$ is an arbitrarily chosen value of $A_{\tau}$. For example, the Chebyshev-Gauss-Lobatto collocation points can be used. They are defined as follows: ${ }^{12}$

$$
\begin{aligned}
A_{i} & =\frac{A_{\tau}}{2}\left(\theta_{i}+1\right), \text { and } \\
\theta_{i} & =\cos \left(\frac{i \pi}{N}\right) .
\end{aligned}
$$

Applying such a collocation method, the initial problem is reduced to that of solving a set of $N+1$ non linear equations:

$$
R F_{i}\left(A_{i}, \mathbf{c}\right)=0, i=0,1, \ldots, N .
$$

Boundary conditions, i.e. the value matching and smooth pasting conditions, need then to be considered. For instance, let us start by introducing the value matching condition. Choosing an initial value $\widehat{A}_{\tau}$ for $A$, equation $(36)$ and equation (34) imply that:

$$
\widehat{V}\left(\widehat{A}_{\tau}\right)-W\left(\widehat{A}_{\tau}-\beta\right)=0 .
$$

To impose that our solution satisfies the value matching, one condition of the set (38) is then replaced by equation (39). The resulting system can be solved iteratively starting with a guess $c^{0}=\left(c_{i}^{0}\right)$. Specifically, we use Newton's method: $c^{k+1}=c^{k}-\left(J_{\mathbf{c}^{k}}\right)^{-1} P\left(c^{k}\right)$, where $J_{\mathbf{c}^{k}}$ is the Jacobian of $R F(A, c)$ evaluated at the respective point $c^{k}$. Finally, the optimal switching time $A_{\tau}$ is found using a search algorithm in order satisfy the smooth pasting condition. We solve for our non-linear system until a value $\widehat{A}_{\tau}=A_{\tau}$ is found that solves:

$$
\widehat{V}^{\prime}\left(\widehat{A}_{\tau}\right)=W^{\prime}\left(\widehat{A}_{\tau}-\beta\right)
$$

\subsection{Results}

In our computations we are using $N=10$ and the baseline parameters' values described in the previous section (with no discounting) except that $\rho=0.0001$. Such a small value allows to compare the results with those obtained under the assumption of no-discounting. ${ }^{13}$ Simulations are driven using MatLab software. In the following figures we show the value functions before and after the switch and the optimal switching level of wealth $A_{\tau}$ :

\footnotetext{
${ }^{12}$ The Gauss-Lobatto-Collocation points are defined for $-1 \leq \theta_{i} \leq 1$. The points $A_{i}$ are a linear transformation of $\theta_{i}$ such that $0 \leq A_{i} \leq A_{\tau}$.

${ }^{13} \mathrm{~A}$ more realistic value for $\rho$ can be found in the sensitivity analysis.
} 


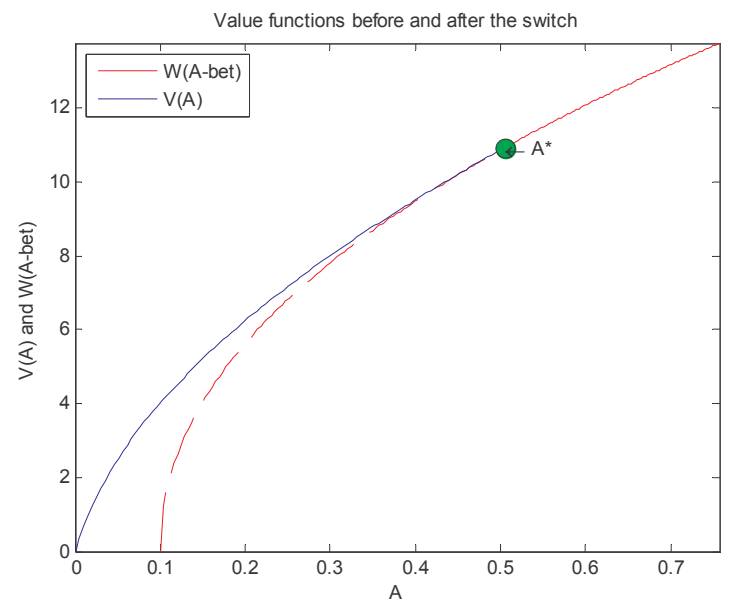

$\gamma<1$. Then $A_{\tau}=0.5049$.

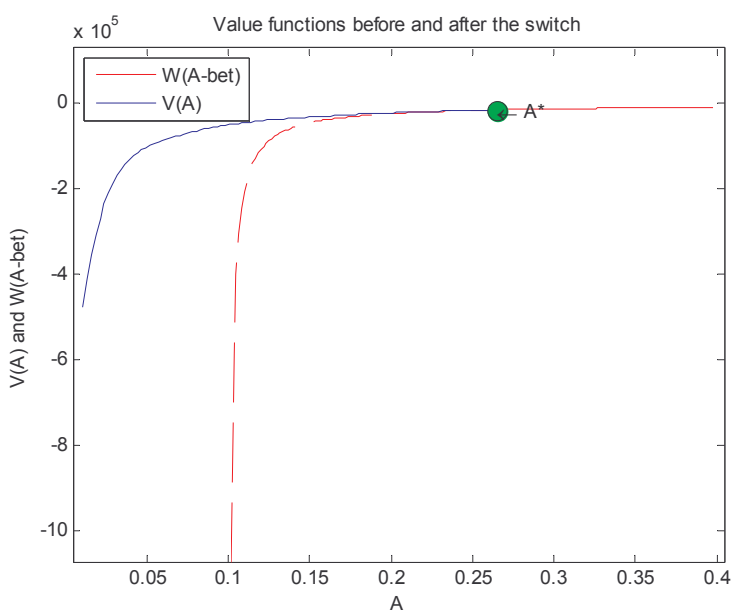

$\gamma>1$. Then $A_{\tau}=0.2653$.

\subsection{Comparative statics}

Figures in the appendix $\mathrm{C}$ show the sensitivity of the optimal adoption timing to the model parameters, starting with the usual baseline. First, this analysis proves to be fully consistent with that driven under the no-discounting assumption. Second, the figures show that the more concerned about the present the household is (larger $\rho$ ), the earlier he adopts the new technology, in order to get the benefits sooner. 


\section{Conclusion}

In this paper we consider a homeowner who makes an irreversible energy-saving investment under uncertainty. Both financial returns and the energy-saving technology efficiency are stochastic. In a general equilibrium framework, we solve the program corresponding to the optimal adoption of an energy-efficiency technology adoption by a representative consumer who uses his wealth to save or to consume energy goods and non-energy goods. The model can only be solved analytically if the utility discount factor is zero. We confirm the results in the more general case with non-zero discounting using a numerical procedure. We show that the threshold triggering adoption depends not only on technological parameters but on preference parameters as well. In particular, the higher the risk aversion parameter, the smaller the level of wealth which is required for adoption. Finally, we also show that while uncertainty on energy-saving technologies efficiency does not affect adoption timing, uncertainty on financial returns fosters it. The latter result is strikingly different from what is obtained in partial equilibrium. 


\section{References}

ANAH (2008), "Modélisation des Performances Energétiques du Parc de Logements", Etat énergétique du parc en 2008.

Ansar, J., and Sparks, R. (2009), "The Experience Curve, Option Value, and the Energy Paradox", Energy Policy, 37 (3), 2012:2020.

Banfi, S. Farsi M., Filippini M. and Jacob M. (2008), "Willingness to Pay for Energy Saving Measures in Residential Buildings", Energy Economics, 30 (2), 503:516.

Brown, M. (2001), "Market Failures and Barriers as a Basis for Clean Energy Policies", Energy Policy, 29(14), 1197:1207.

Boulanger, P.-M. (2007), "Les Barrières à l'Efficacité Energétique", Reflets et perspectives de la vie économique, Tome XLVI, 49:6.

Dangl, T., \& Wirl, F. (2004)." Investment under uncertainty: calculating the value function when the Bellman equation cannot be solved analytically." Journal of Economic Dynamics \& Control , 28 (7), 1437:1461.

Diaz-Rainey I. and Ashton J. (2009), "Domestic Energy Efficiency Measures, Adopter Heterogeneity and Policies to Induce Diffusion", Working Paper SSRN.

Dixit, A. K., and Pindyck, R. S. (1994), "Investment under Uncertainty", Princeton University Press.

Farsi M. (2009), "Risk Aversion and Willingness to Pay for Energy Efficient Systems in Rental Apartments", Working Paper, ETH Zurich, Switzerland.

Hassett, K. A., and Metcalf, G. E. (1993), "Energy Conservation Investment: Do Consumers Discount the Future Correctly?", Energy Policy, 21 (6), 710:716.

Hassett, K. A., and Metcalf, G. E. (1995), "Energy Tax Credits and Residential Conservation Investment: Evidence from Panel Data", Journal of Public Economics, 57 (2), 201:217.

Hausman, J. A. (1979), "Individual Discount Rates and the Purchase and Utilization of Energy-Using Durables", The Bell Journal of Economics, 10 (1), 33:54.

Hugonnier, J., Morellec E., and Sundaresan S. (2005), "Irreversible Investment in General Equilibrium", Working paper FR 05-10, Simon School of Business.

Hugonnier, J., Pelgrin, F. and Pommeret A. (2008), "Technology Adoption under Uncertainty in General Equilibrium" Working paper, University of Lausanne. 
Jaffe, A. B., and Stavins, R. N. (1994a), "Energy-Efficiency Investments and Public Policy" Energy Journal, 15 (2), 43:65.

Jaffe, A. B., and Stavins, R. N. (1994b), "The Energy-Efficiency Gap. What Does it Mean?", Energy Policy, 22 (10), 804:810.

Jakob M. (2006), "Marginal Costs, Cost Dynamics and Co-Benefits of Energy Efficiency Investments in the Residential Buildings Sector", Energy Policy, 34 (2), 172:187.

Judd K;L, (1992), "Projection Methods for Solving Aggregate Growth Models", Journal of Economic theory, 58, 410:452.

Judd K.L, (1998), "Numerical Methods in Economics", The MIT press.

Ott, W., M. Baur and Jakob M. (2006), "Direkte und Indirekte Zusatznutzen bei Energie-Effizienten Wohnbauten" (Direct and indirect additional benefits of energy efficiency in residential buildings), Final report (in German) of a joint study by Econcept and ETH-Zurich, Switzerland.

Pommeret,A. and Schubert, K. (2009), "Abatement Technology Adoption under Uncertainty", Macroeconomic Dynamics, volume 13, issue 04, 493:522.

Sanstad, A.H., Blumstein, C., and Stoft, S.E. (1995), "How High are Option Values in Energy-Efficiency Investments?", Energy Policy, 23(9), 730:743.

Sanstad, A.H., and Howarth, R.B. (1994), "Normal Markets, Market Imperfections and Energy Efficiency", Energy Policy, 22(10): 811:818.

Smith W. T., 1996, "Feasibility and Transversality Conditions for Models of PortfolioChoice with Non-expected Utility in Continuous Time", Economics Letters, 53:123-131.

Smith W. T. and Y. S. Son, 2005, "Can the Desire to Conserve our Natural Resources be Self-defeating?", Journal of Environmental Economics and Management, 49:52-67. 


\section{Appendix}

\section{A Solving the optimal program after adoption}

The Bellman equation is written as:

$$
W\left(A_{t}\right)=\max _{C_{1 t}, C_{2 t}}\left\{\frac{\left(C_{1 t}^{a} C_{2 t}^{b}\right)^{1-\gamma}}{1-\gamma} d t+E_{t}\left(W\left(A_{t+d t}\right)\right)\right\} \text { with } t \geq \tau
$$

Using Itô's lemma, this equation becomes:

$$
\max _{C_{1 t}, C_{2 t}}\left\{\frac{\left(C_{1 t}^{a} C_{2 t}^{b}\right)^{1-\gamma}}{1-\gamma} d t+W_{A}\left(r A-C_{1}-y C_{2}\right) d t+\left[\frac{\sigma_{1}^{2}}{2} y^{2} C_{2}^{2}+\frac{\sigma_{2}^{2}}{2} r^{2} A^{2}\right] W_{A A} d t\right\}=0
$$

The first order conditions yields:

$$
C_{1 t}^{*}=\left[W_{A} \frac{C_{2 t}^{-b(1-\gamma)}}{a}\right]^{\frac{1}{a(1-\gamma)-1}} \text { and } C_{2 t}^{*}=\frac{y W_{A}}{b C_{2 t}^{b(1-\gamma)-2} C_{1 t}^{a(1-\gamma)}+\sigma_{1}^{2} y^{2} W_{A A}}
$$

We guess that $C_{2 t}^{*}=B \cdot A$ and $W\left(A_{t}\right)=W\left(A_{t}\right)=\frac{M A^{1-R}}{(1-\gamma)}$, with $B$ and $M$ being constant to de determined and $R=1-(a+b)(1-\gamma)$ being the effective coefficient of risk aversion (equation (5) in the text). Then:

$$
\begin{gathered}
W_{A}=M(a+b) A^{(a+b)(1-\gamma)-1} \\
W_{A A}=M(a+b)[(a+b)(1-\gamma)-1] A^{(a+b)(1-\gamma)-2}
\end{gathered}
$$

By replacing the consumptions by their optimal expressions into the bellman equation we get:

$$
\begin{aligned}
0= & \frac{1}{1-\gamma}\left[\left(\frac{W_{A}(B A)^{-b(1-\gamma)}}{a}\right)^{\frac{a(1-\gamma)}{a(1-\gamma)-1}}(B A)^{b(1-\gamma)}\right] \\
& +W_{A}\left[r A-\left(\frac{W_{A}(B A)^{-b(1-\gamma)}}{a}\right)^{\frac{1}{a(1-\gamma)-1}}-y(B A)\right]+W_{A A}\left[\frac{\sigma_{1}^{2}}{2} y^{2}(B A)^{2}+\frac{\sigma_{2}^{2}}{2} A^{2}\right]
\end{aligned}
$$


$\Leftrightarrow M^{\frac{1}{a(1-\gamma)-1}} B^{\frac{-b(1-\gamma)}{a(1-\gamma)-1}}=\left(\frac{a}{a+b}\right)^{\frac{1}{1-a(1-\gamma)}}\left(\frac{a(1-\gamma)}{1-a(1-\gamma)}\right)\left[\frac{R}{2}\left(\sigma_{1}^{2} y^{2} B^{2}+\sigma_{2}^{2}\right)-r+y B\right]$

Moreover, using the expression of $C_{2 t}^{*}$ we can get:

$$
M^{\frac{1}{a(1-\gamma)-1}} B^{\frac{-b(1-\gamma)}{a(1-\gamma)-1}}=\frac{B}{b} a^{\frac{a(1-\gamma)}{a(1-\gamma)-1}}(a+b)^{\frac{1}{1-a(1-\gamma)}}\left(y+R \sigma_{1}^{2} y^{2} B\right)
$$

Hence:

$$
\begin{gathered}
\left(\frac{1-\gamma}{1-a(1-\gamma)}\right)\left[\left(\sigma_{1}^{2} y^{2} B^{2}+\sigma_{2}^{2}\right) \frac{R}{2}-r+y B\right]=\frac{B}{b}\left(y+R \sigma_{1}^{2} y^{2} B\right) \\
\Leftrightarrow B^{2}\left[\frac{R}{2} \sigma_{1}^{2} y^{2}\left(\frac{1-\gamma}{[1-a(1-\gamma)]}-\frac{2}{b}\right)\right]+B\left[y\left(\frac{(1-\gamma)}{1-a(1-\gamma)}-\frac{1}{b}\right)\right] \\
\quad+\left[\frac{\rho}{1-R}-r+\frac{R}{2} \sigma_{2}^{2}\right]\left(\frac{1-\gamma}{1-a(1-\gamma)}\right)=0 \\
\Leftrightarrow B^{2}\left[\frac{R}{2} \sigma_{1}^{2} y^{2}\left(b-2 \frac{[1-a(1-\gamma)]}{1-\gamma}\right)\right]+B\left[y\left(b-\frac{[1-a(1-\gamma)]}{1-\gamma}\right)\right]+\left[b \frac{R}{2} \sigma_{2}^{2}-b r+\frac{b \rho}{1-R}\right]=0 \\
\Leftrightarrow B^{2}\left[\frac{R}{2} \sigma_{1}^{2} y^{2}\left(2 a+b-\frac{2}{1-\gamma}\right)\right]+B\left[y\left(a+b-\frac{1}{1-\gamma}\right)\right]+\left[b \frac{R}{2} \sigma_{2}^{2}-b r+\frac{b \rho}{1-R}\right]=0 \\
\Delta=\left[y\left(a+b-\frac{1}{1-\gamma}\right)\right]^{2}-4\left[\frac{R}{2} \sigma_{1}^{2} y^{2}\left(2 a+b-\frac{2}{(1-\gamma)}\right)\right]\left[b \frac{R}{2} \sigma_{2}^{2}-b r+\frac{b \rho}{1-R}\right]
\end{gathered}
$$

Therefore:

$$
\begin{aligned}
B & =\frac{-y((a+b)(1-\gamma)-1) \pm(1-\gamma) \sqrt{\Delta}}{R \sigma_{1}^{2} y^{2}[(2 a+b)(1-\gamma)-2]} \\
& =\frac{-y((a+b)(1-\gamma)-1) \pm(1-\gamma) \sqrt{\Delta}}{R \sigma_{1}^{2} y^{2}[2(a+b)(1-\gamma)-2-b(1-\gamma)]} \\
& =\frac{R y \pm(1-\gamma) \sqrt{\Delta}}{R \sigma_{1}^{2} y^{2}[2 R-b(1-\gamma)]}
\end{aligned}
$$

$W\left(A_{t}\right)=B^{b(1-\gamma)}\left[\frac{B}{b} a^{\frac{a(1-\gamma)}{a(1-\gamma)-1}}(a+b)^{\frac{1}{1-a(1-\gamma)}}\left(y+R \sigma_{1}^{2} y^{2} B\right)\right]^{[a(1-\gamma)-1]} \frac{A^{(a+b)(1-\gamma)}}{(1-\gamma)}$

We insert the expression of the effective coefficient of risk aversion in the precedent equation and we obtain (equation 12 of the text): 
$W\left(A_{t}\right)=B^{b(1-\gamma)}\left[\frac{B}{b} a^{\frac{a(1-\gamma)}{a(1-\gamma)-1}}(a+b)^{\frac{1}{1-a(1-\gamma)}}\left(y+R \sigma_{1}^{2} y^{2} B\right)\right]^{[a(1-\gamma)-1]} \frac{A^{1-R}}{(1-\gamma)}$

Moreover, consumption expenditure can be affected by uncertainty. Effects of $\sigma_{2}^{2}$ on $C_{1 t}$ if $\gamma>1$ or of $\sigma_{1}^{2}$ on both $C_{1 t}$ and $C_{2 t}$ are analytically indeterminate. The following figures provide a numerical computation of these effects based on the set of parameters' values described in section 4.2 .

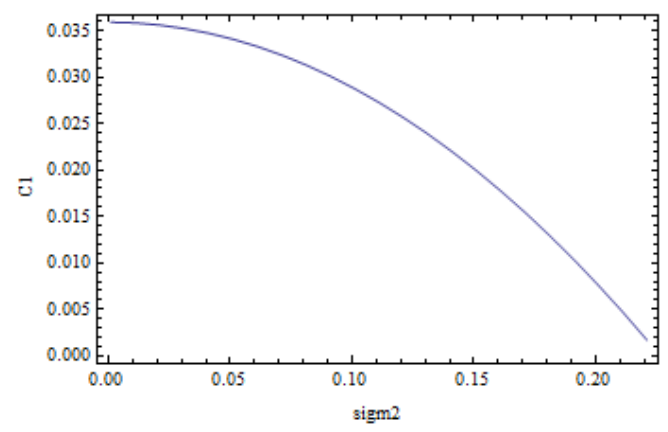

Figure : Effect of $\sigma_{2}^{2}$ on $C_{1 t}$ when $\gamma>1$
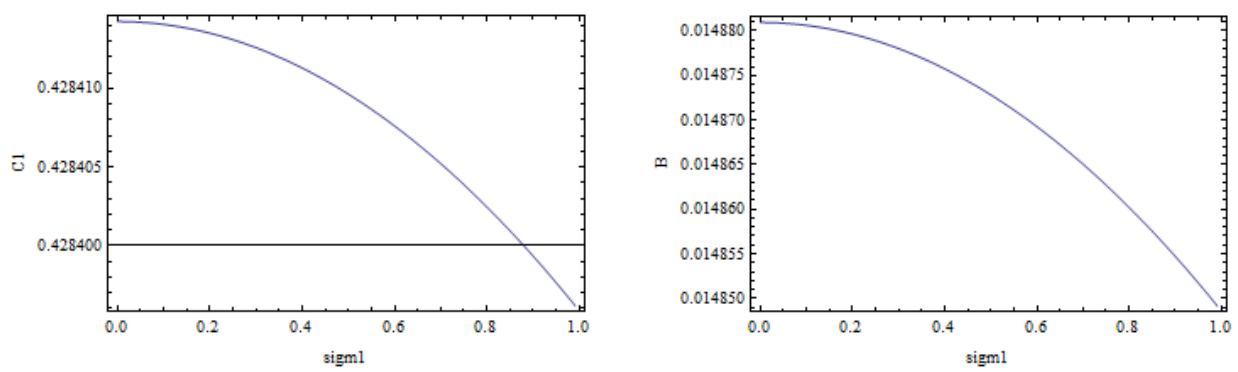

Figure : Effects of of $\sigma_{1}^{2}$ on both $C_{1 t}$ and $C_{2 t}$ when $\gamma<1$
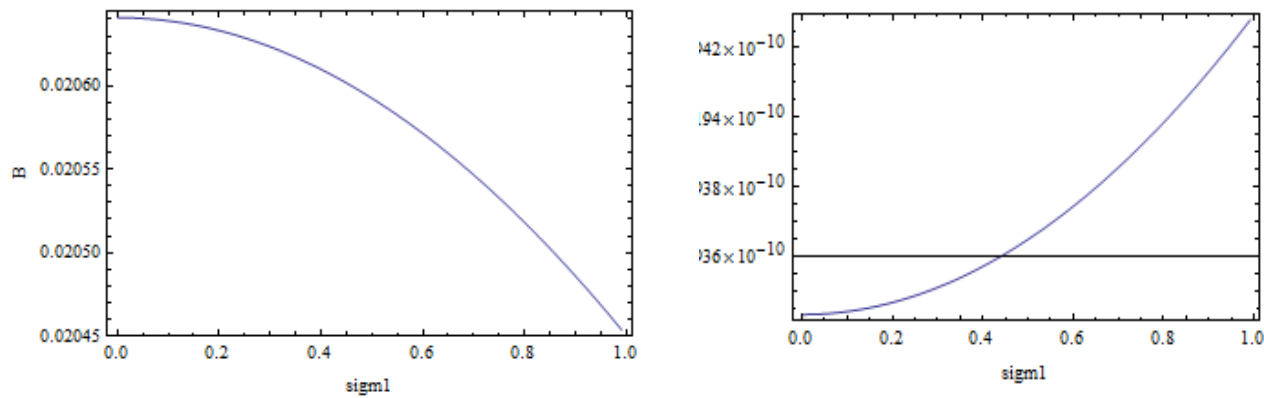

Figure : Effects of $\sigma_{1}^{2}$ on both $C_{1 t}$ and $C_{2 t}$ when $\gamma>1$ 


\section{B Solving the optimal program before adoption}

Using Itô's lemma, the value function before adoption $V(A \tau)_{\{t<\tau\}}$ has to satisfy:

$$
\max _{C_{1 t}, C_{2 t}}\left\{\frac{\left(C_{1 t}^{a} C_{2 t}^{b}\right)^{1-\gamma}}{1-\gamma} d t+V_{A}\left(r A-C_{1}-x C_{2}\right) d t+\frac{1}{2} \sigma_{2}^{2} A^{2} V_{A A} d t\right\}=0
$$

The first order conditions yield:

$$
\begin{aligned}
& a C_{1 t}^{a(1-\gamma)-1} C_{2 t}^{b(1-\gamma)}=V_{A} \\
& C_{1 t}^{a(1-\gamma)} b C_{2 t}^{b(1-\gamma)-1}=x V_{A}
\end{aligned}
$$

Therefore:

$$
\begin{gathered}
C_{1 t}^{*}=\left[a^{1-b(1-\gamma)}\left(\frac{b}{x}\right)^{b(1-\gamma)}\right]^{\frac{1}{R}} V_{A}^{\frac{-1}{R}} \\
C_{2 t}^{*}=a^{\frac{a(1-\gamma)}{R}}\left(\frac{b}{x}\right)^{\frac{1-a(1-\gamma)}{R}} V_{A}^{\frac{-1}{R}}
\end{gathered}
$$

Replacing consumption by its optimal expression in the Bellman equation and multiplying by $V_{A}^{\frac{1-R}{R}}$ yields:

$$
\frac{R}{1-\gamma} a^{\frac{a(1-\gamma)}{R}}\left(\frac{b}{x}\right)^{\frac{b(1-\gamma)}{R}}+A V_{A}^{\frac{1}{R}} r+\frac{1}{2} \sigma_{2}^{2} A^{2} V_{A}^{\frac{1-R}{R}} V_{A A}=0
$$

We make the following variable change: $f\left(A_{t}\right)=V_{A}^{\frac{1}{R}}$ and $f^{\prime}\left(A_{t}\right)=$ $\frac{1}{R} V_{A}^{\frac{1-R}{R}} V_{A A}$. Hence, the preceding equation may be written as:

$$
\frac{R}{1-\gamma} a^{\frac{a(1-\gamma)}{R}}\left(\frac{b}{x}\right)^{\frac{b(1-\gamma)}{R}}+f\left(A_{t}\right) A_{t} r+\frac{1}{2} \sigma_{2}^{2} A_{t}^{2} R f^{\prime}\left(A_{t}\right)=0
$$

We guess that $f\left(A_{t}\right)$ can be written as follows:

$$
f\left(A_{t}\right)=\frac{D_{1}}{A_{t}}+D_{2} A_{t}^{D_{3}} \Rightarrow f^{\prime}\left(A_{t}\right)=-\frac{D_{1}}{A_{t}^{2}}+D_{2} D_{3} A_{t}^{D_{3}-1}
$$

where $D_{1}, D_{2}$ and $D_{3}$ are constants to be determined. Then: 
$\frac{R}{1-\gamma} a^{\frac{a(1-\gamma)}{R}}\left(\frac{b}{x}\right)^{\frac{b(1-\gamma)}{R}}+\left(\frac{D_{1}}{A_{t}}+D_{2} A_{t}^{D_{3}}\right) A_{t} r+\frac{1}{2} \sigma_{2}^{2} R A_{t}^{2}\left(-\frac{D_{1}}{A_{t}^{2}}+D_{2} D_{3} A_{t}^{D_{3}-1}\right)=0$

This equation is of the form:

$$
g\left(A_{t}\right)+v=0
$$

In order for this condition to be satisfied whatever $A_{t}$, one must have: $g\left(A_{t}\right)=0$ and $v=0$

Therefore:

$$
\begin{gathered}
\frac{R}{1-\gamma} a^{\frac{a(1-\gamma)}{R}}\left(\frac{b}{x}\right)^{\frac{b(1-\gamma)}{R}}+D_{1}\left(r-\frac{1}{2} \sigma_{2}^{2} R\right)=0 \\
\text { and } \\
r+\frac{1}{2} \sigma_{2}^{2} R D_{3}=0
\end{gathered}
$$

Thus, we obtain $D_{1}$ and $D_{3}$ :

$$
\begin{gathered}
D_{1}=\left[\frac{R}{\gamma-1} a^{\frac{a(1-\gamma)}{R}}\left(\frac{b}{x}\right)^{\frac{b(1-\gamma)}{R}}\right] \frac{1}{\left(r-\frac{1}{2} \sigma_{2}^{2} R\right)} \\
D_{3}=-\frac{r}{\frac{1}{2} R \sigma_{2}^{2}}
\end{gathered}
$$

We show that the marginal value of wealth before the switch is:

$$
V_{A}\left(A_{t}\right)=[\underbrace{\frac{\frac{R}{\gamma-1} a^{\frac{a(1-\gamma)}{R}}\left(\frac{b}{x}\right)^{\frac{b(1-\gamma)}{R}}}{\left(r-\frac{1}{2} \sigma_{2}^{2} R\right)}}_{D_{1}} A_{t}^{-1}+D_{2} A_{t}^{-\frac{r}{\frac{1}{2} R \sigma_{2}^{2}}}]^{R}
$$

$D_{2}$ is a constant which must be determined using the smooth pasting condition (see equation (14) of the text). From the last equation we obtain:

$$
\begin{aligned}
V_{A}^{\frac{1}{R}} & =f(A)=\frac{D_{1}}{A}+D_{2} A^{D_{3}} \\
& \Rightarrow \quad V_{A}=\left[\frac{D_{1}}{A}+D_{2} A^{D_{3}}\right]^{R}
\end{aligned}
$$


and using the smooth pasting condition (equation (14) in the text):

$$
V_{A}=W_{A}\left(A_{\tau}-\beta\right)=M(a+b)\left(A_{\tau}-\beta\right)^{-R} .
$$

Hence:

$$
\begin{aligned}
{\left[\frac{D_{1}}{A_{\tau}}+D_{2} A_{\tau}^{D_{3}}\right]^{R} } & =M(a+b)\left(A_{\tau}-\beta\right)^{-R} \\
& \Leftrightarrow \frac{D_{1}}{A_{\tau}}+D_{2}^{D_{3}} A_{\tau}=\frac{[M(a+b)]^{\frac{1}{R}}}{A_{\tau}-\beta} \\
& \Leftrightarrow D_{2} A_{\tau}^{D_{3}}=\frac{[M(a+b)]^{\frac{1}{R}}}{A_{\tau}-\beta}-\frac{D_{1}}{A_{\tau}} \\
& \Leftrightarrow D_{2}=\frac{[M(a+b)]^{\frac{1}{R}}}{\left(A_{\tau}-\beta\right) A_{\tau}^{D_{3}}}-\frac{D_{1}}{A_{\tau}^{D_{3}+1}} .
\end{aligned}
$$

This is the equation (23) in the text.

$$
\begin{aligned}
& \Longrightarrow V_{A}=\left[\frac{D_{1}}{A_{t}}+\left(\frac{[M(a+b)]^{\frac{1}{R}}}{\left(A_{\tau}-\beta\right) A_{\tau}^{D_{3}}}-\frac{D_{1}}{A_{\tau}^{D_{3}+1}}\right) A_{t}^{D_{3}}\right]^{R} \\
& =[\underbrace{\frac{D_{1}}{A_{t}}}_{W_{0 A}\left(A_{t}\right)^{1 / R}}+(\underbrace{\frac{[M(a+b)]^{\frac{1}{R}}}{\left(A_{\tau}-\beta\right)}}_{W_{A}\left(A_{\tau}-\beta\right)^{1 / R}}-\underbrace{\frac{D_{1}}{A_{\tau}}}_{W_{0 A}\left(A_{\tau}\right)^{1 / R}})\left(\frac{A_{t}}{A_{\tau}}\right)^{D_{3}}]^{R}
\end{aligned}
$$

The expression of the marginal value of wealth can be written as follows:

$$
V_{A}\left(A_{t}\right)=\left[\left[\frac{\frac{R}{\gamma-1} a^{\frac{a(1-\gamma)}{R}}\left(\frac{b}{x}\right)^{\frac{b(1-\gamma)}{R}}}{\left(r-\frac{1}{2} \sigma_{2}^{2} R\right)}\right] A_{t}^{-1}+G(t)\right]^{R}
$$

where $G(t)$ is the option value. It is the equation (20) in the text.

Note that $W_{0}\left(A_{t}\right)$, the value function of the homeowner in an economy with no technological change, has to satisfy:

$$
\begin{aligned}
0 & =\frac{R}{\gamma-1} a^{\frac{a(1-\gamma)}{R}}\left(\frac{b}{x}\right)^{\frac{b(1-\gamma)}{R}}+A W_{0 A} r+\frac{1}{2} \sigma_{2}^{2} A^{2} W_{0 A A} \\
& \Leftrightarrow W_{0}\left(A_{t}\right)=\left[\frac{\frac{R}{\gamma-1} a^{\frac{a(1-\gamma)}{R}}\left(\frac{b}{x}\right)^{\frac{b(1-\gamma)}{R}}}{\left(r-\frac{1}{2} \sigma_{2}^{2} R\right)}\right] \frac{A^{1-R}}{(a+b)(1-\gamma)} \\
& \Leftrightarrow W_{0}\left(A_{t}\right)=D_{1}^{R} \frac{A^{1-R}}{(a+b)(1-\gamma)}
\end{aligned}
$$

Finally, notice that in the special case in which $\sigma_{1}=0$ and $x=y$, we have $M=D_{1}^{R} /(a+b)$. 


\section{Comparative Statics}

- For $\rho=0$ and $\gamma<1$,

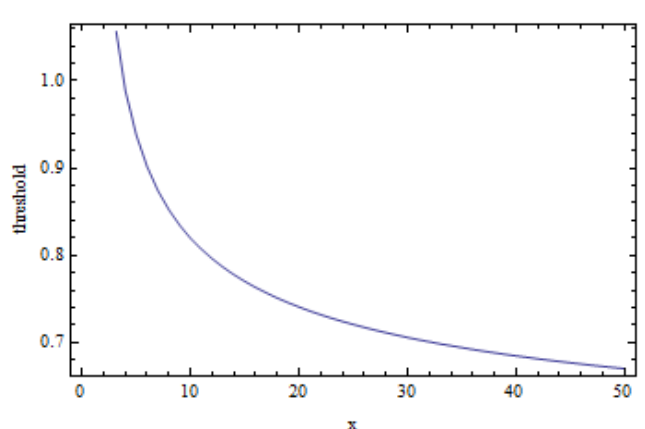

Effect of $x$

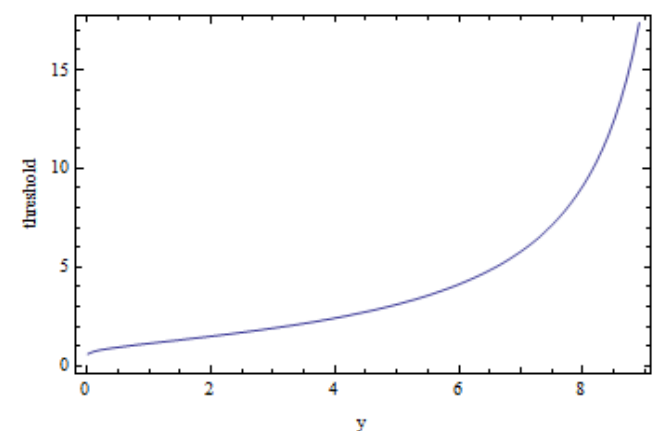

Effect of $y$

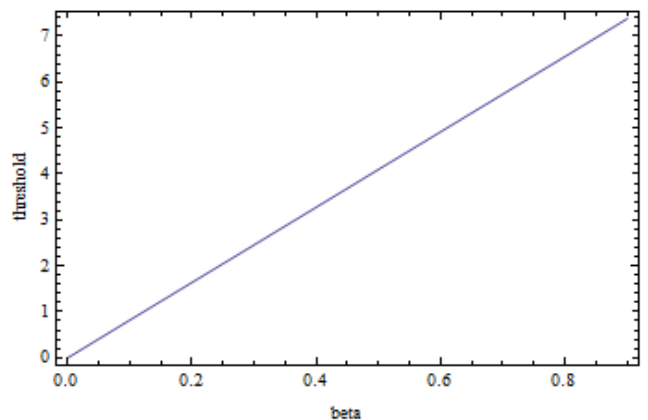

Effect of $\beta$

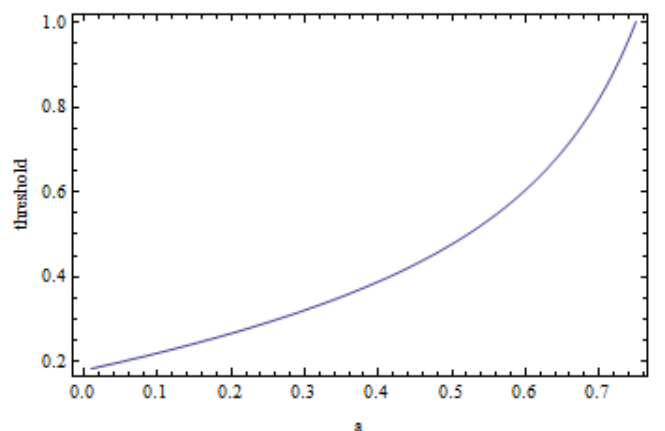

EFfect of $a$

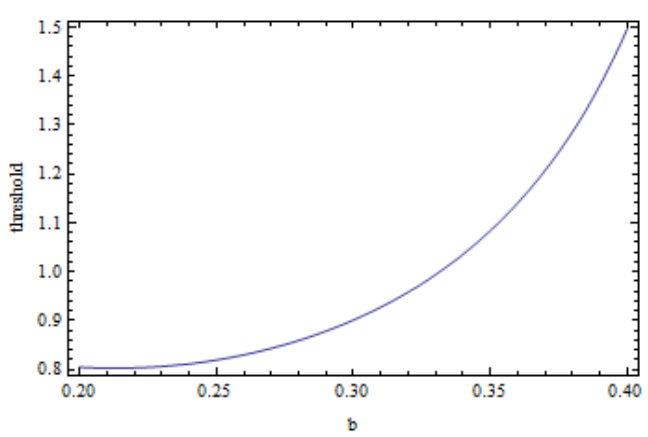

EFfect of $b$ 


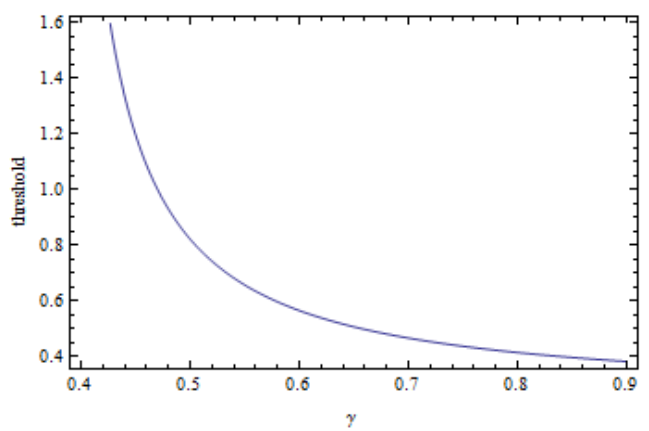

Effect of $\gamma$

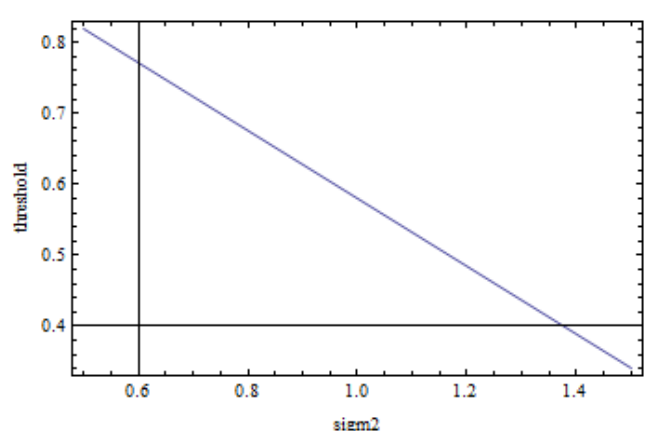

Effect of $\sigma_{2}$

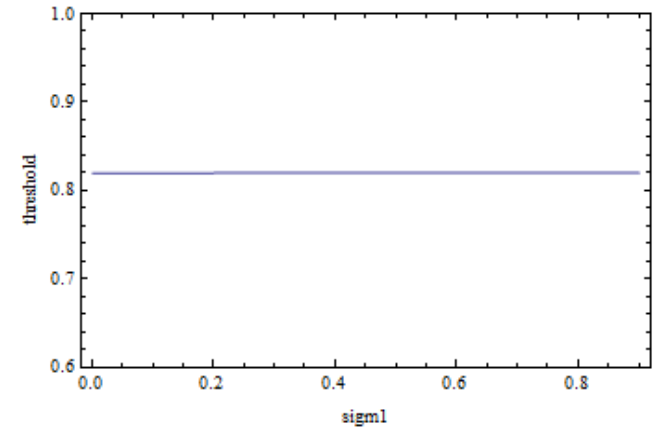

Effect of $\sigma_{1}$

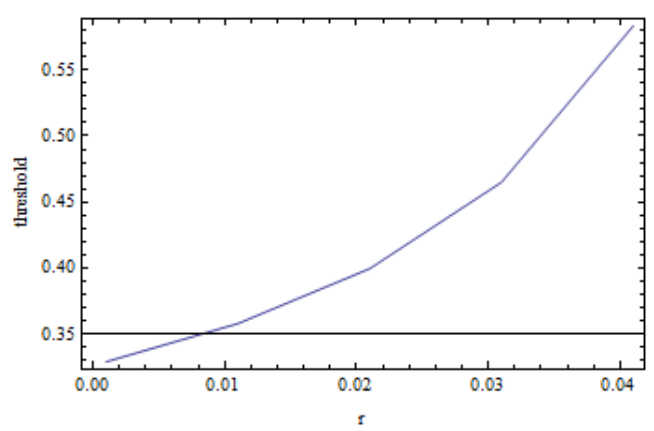

Effect of $r$ 
- For $\rho=0$ and $\gamma>1$,
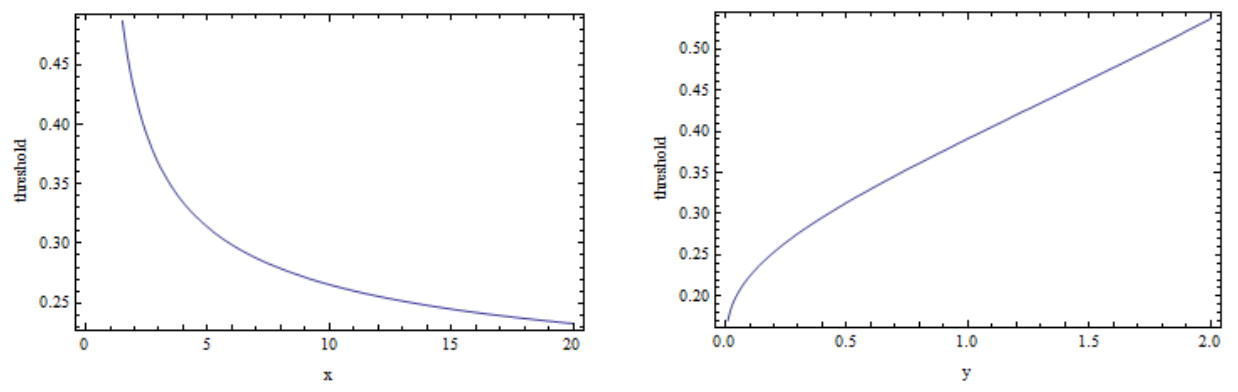

Effect of $x$

Effect of $y$

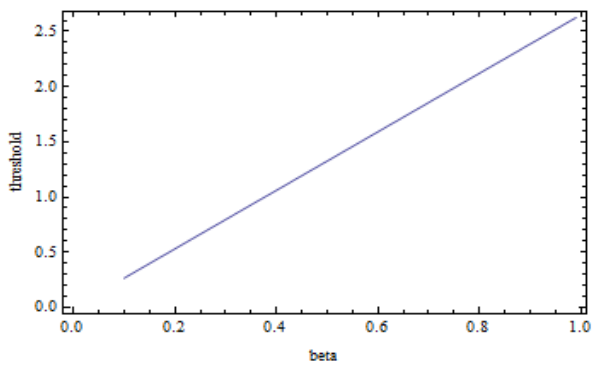

Effect of $\beta$

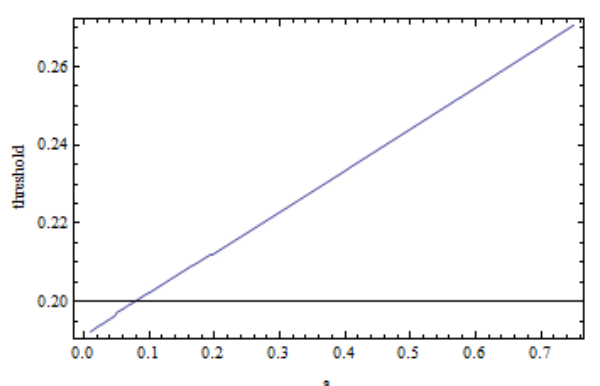

Effect $a$

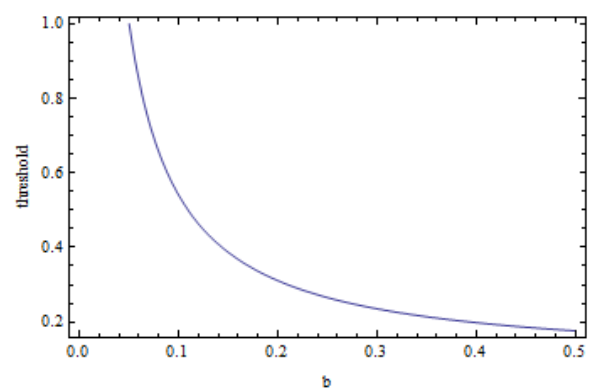

Effect of $b$ 


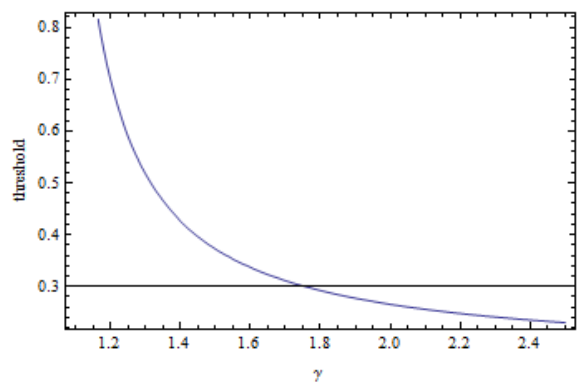

Effect of $\gamma$

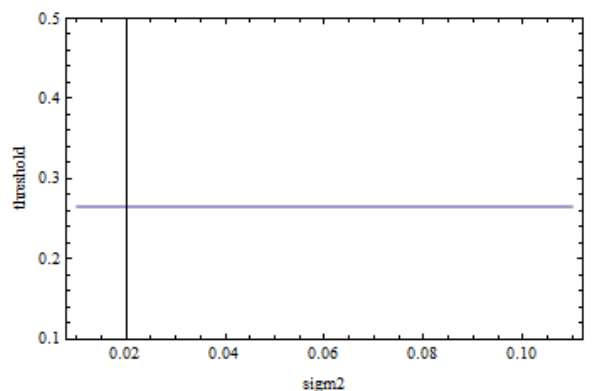

Effect of $\sigma_{2}$

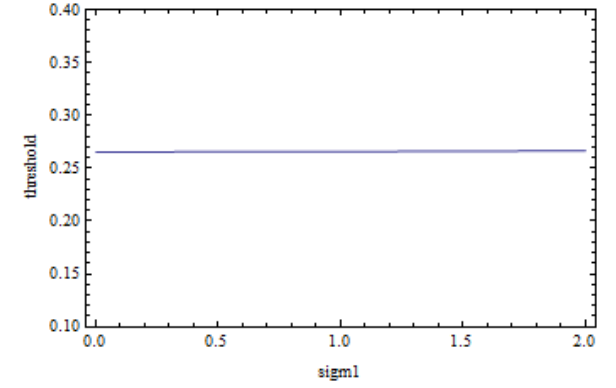

Effect of $\sigma_{1}$

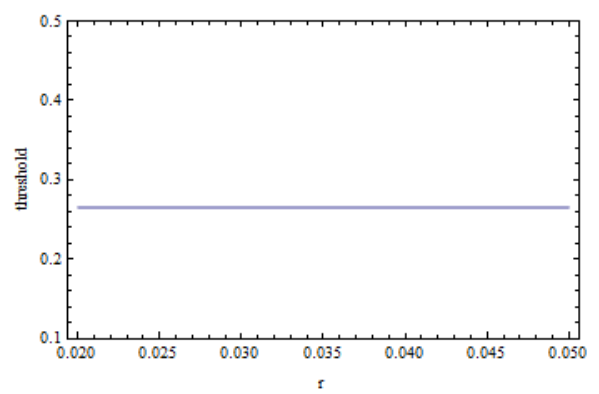

Effect of $r$ 
- For $\rho=0.0001$ and $\gamma<1$

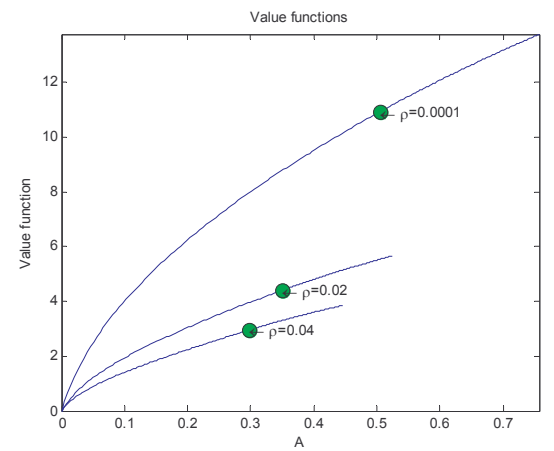

Effect of $\rho$

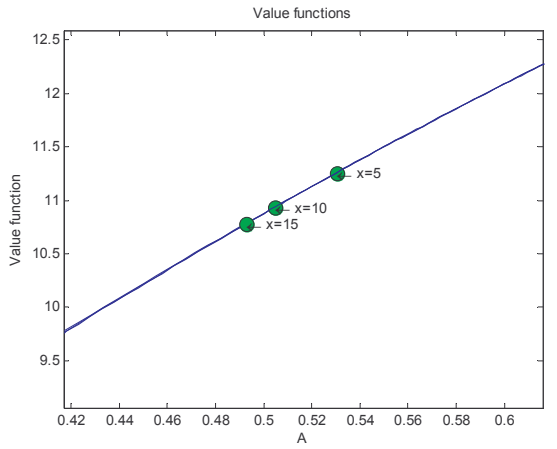

Effect of $x$

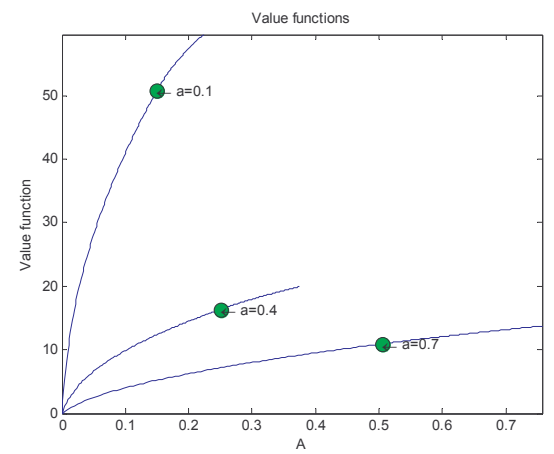

Effect of $a$

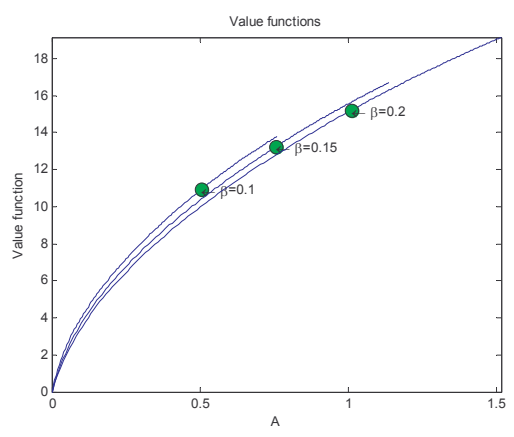

Effect of $\beta$

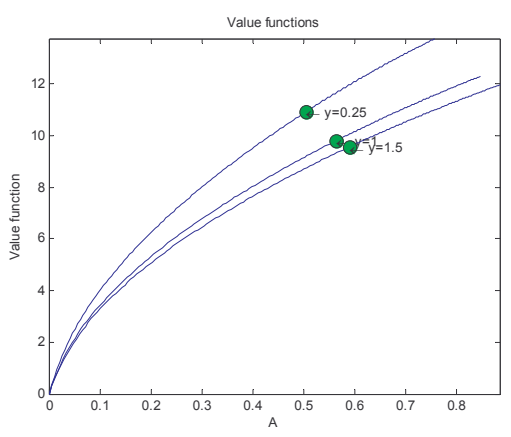

Effect of $y$

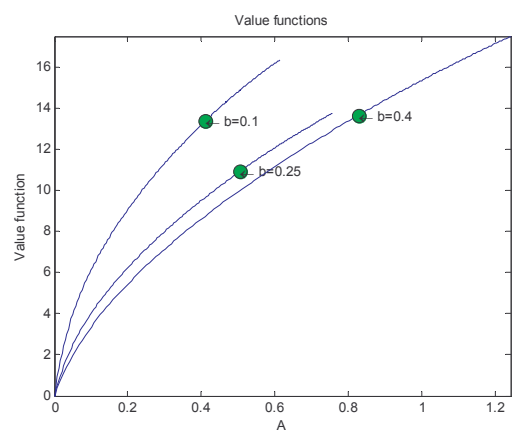

Effect of $b$ 


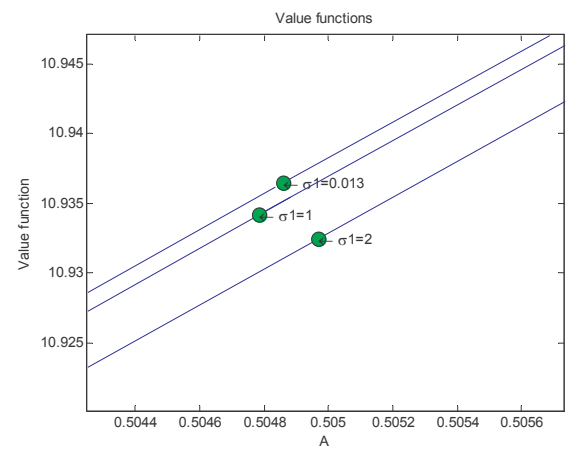

Effect of $\sigma_{1}$

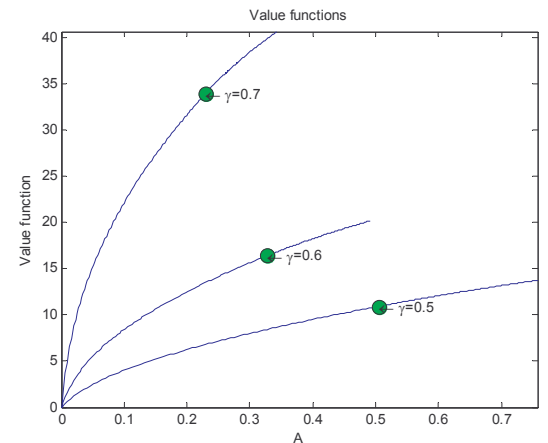

Effect of $\gamma$

- For $\rho=0.0001$ and $\gamma>1$

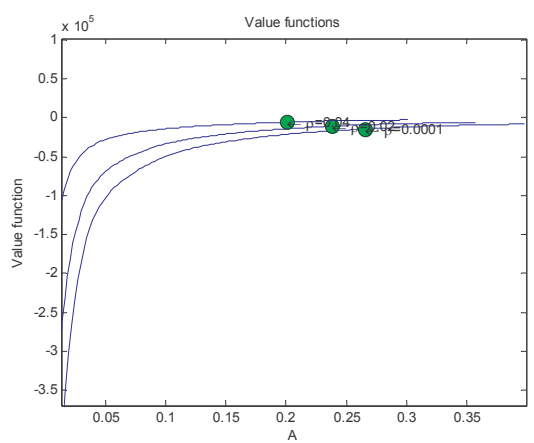

Effect of $\rho$

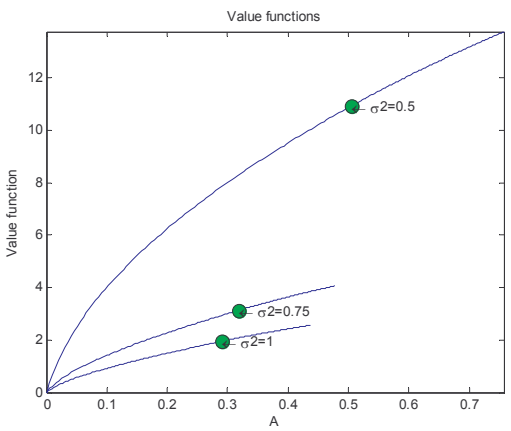

Effect of $\sigma_{2}$

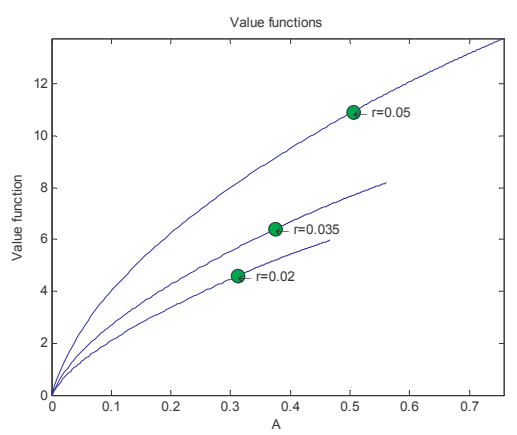

Effect of $r$

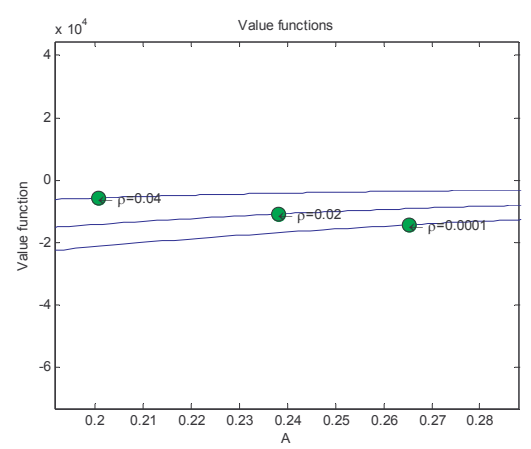

Effect of $\rho$ (zoomed) 

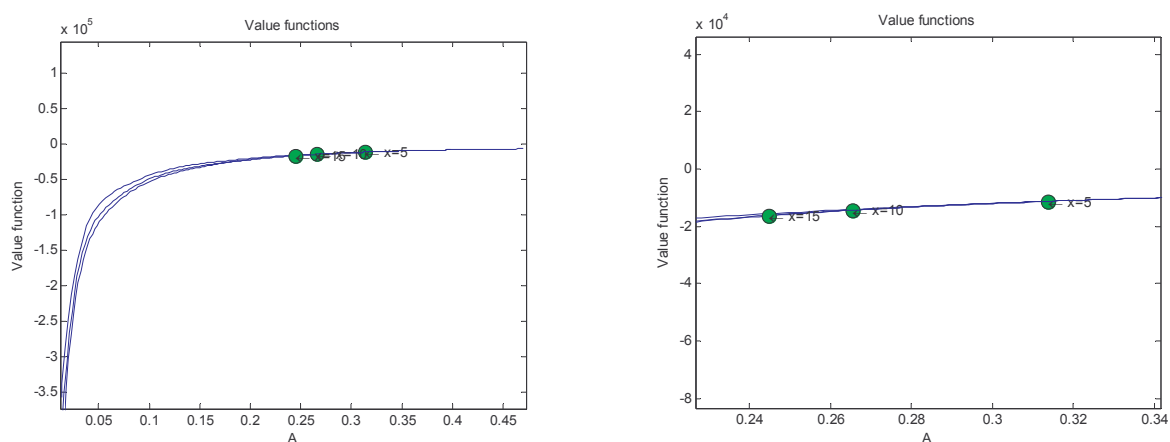

Effect of $x$

Effect of $x$ (zoomed)
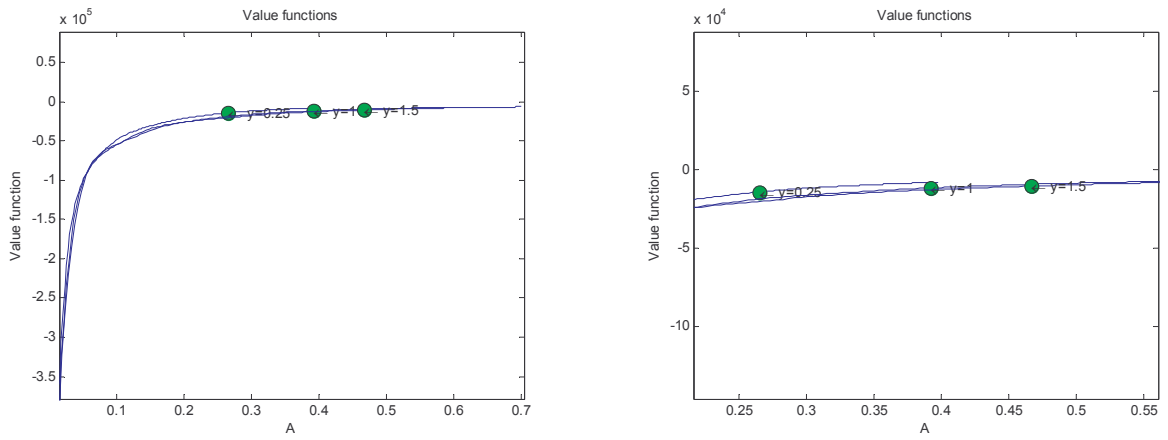

Effect of $y$

Effect of $y$ (zoomed)

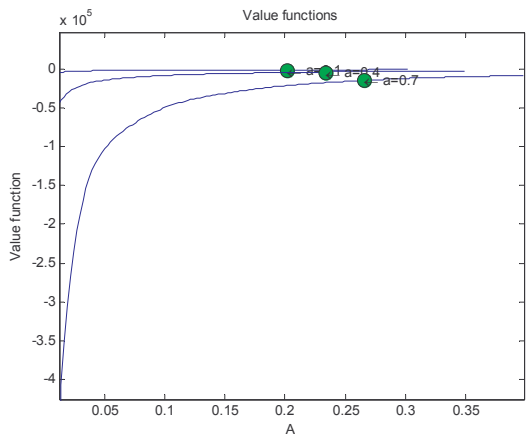

Effect of $a$

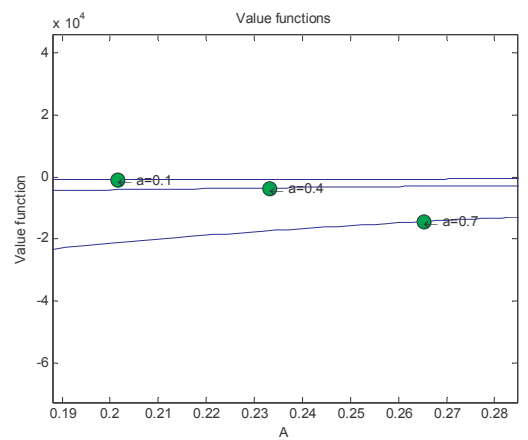

Effect of $a$ (zoomed) 


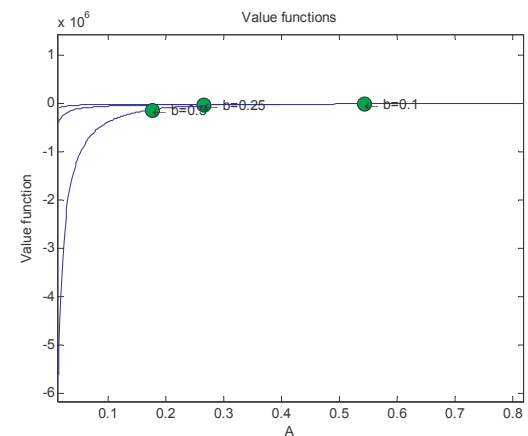

Effect of $b$

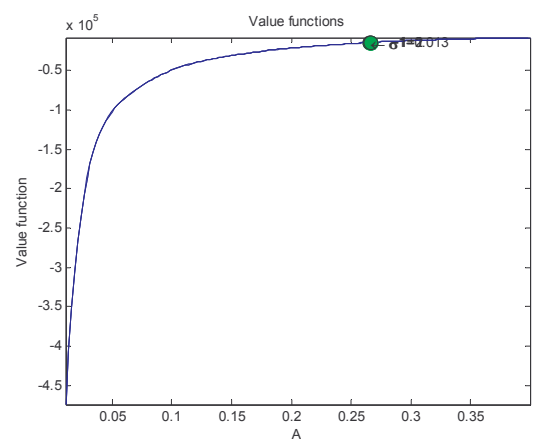

Effect of $\sigma_{1}$

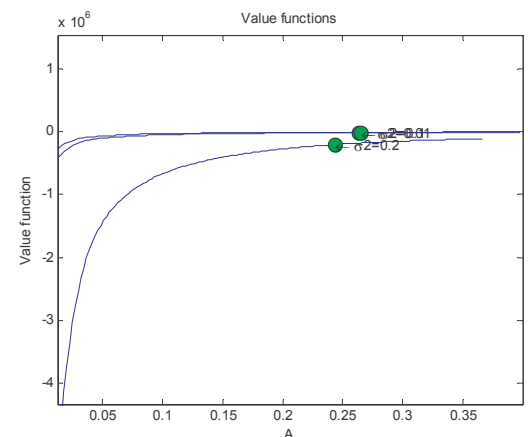

Effect of $\sigma_{2}$

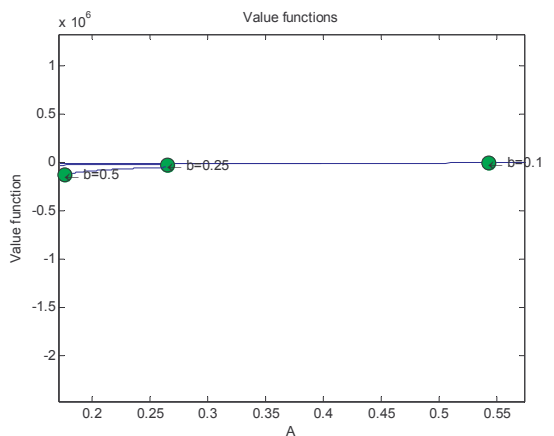

Effect of $b$ (zoomed)

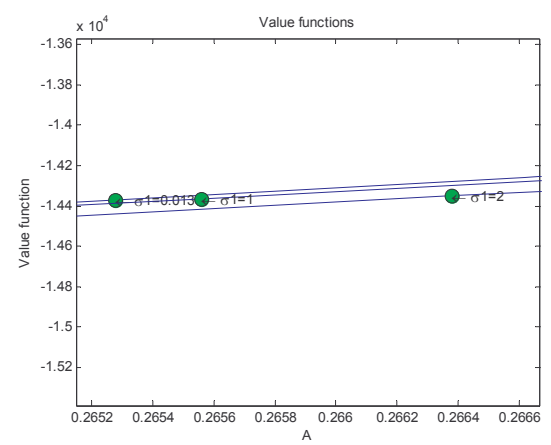

Effect of $\sigma_{1}$ (zoomed)

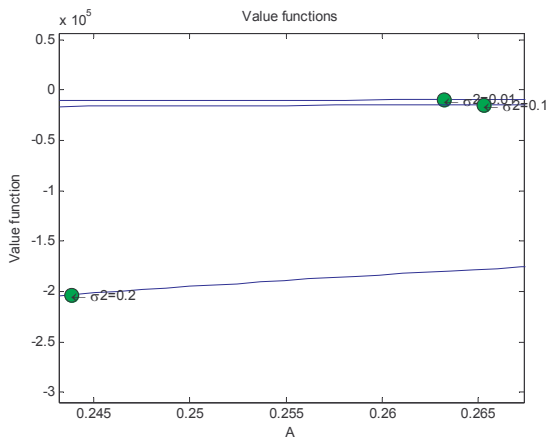

Effect of $\sigma_{2}$ (zoomed) 

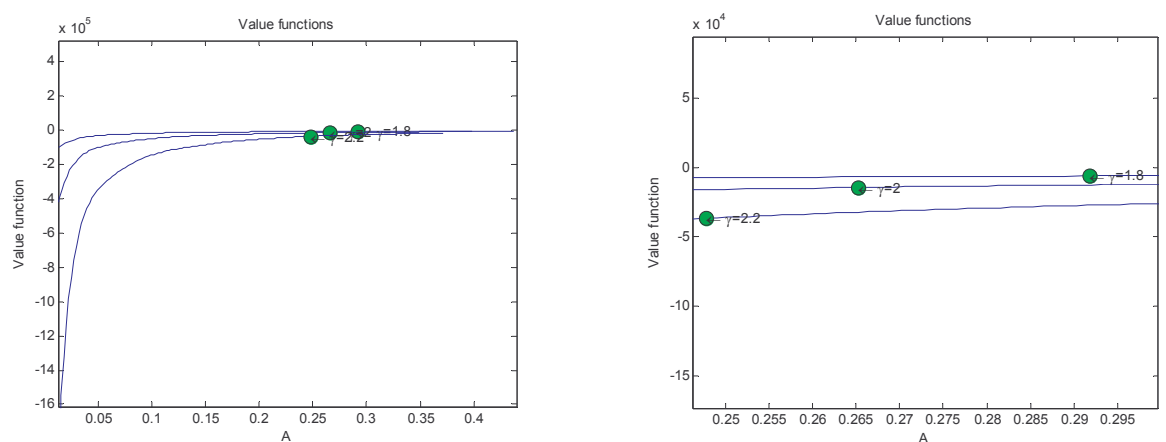

Effect of $\gamma$

Effect of $\gamma$ (zoomed)

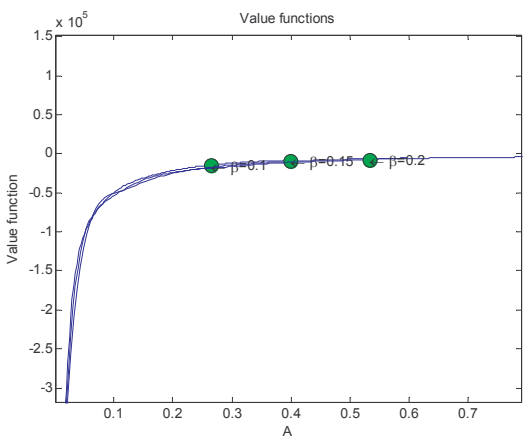

Effect of $\beta$

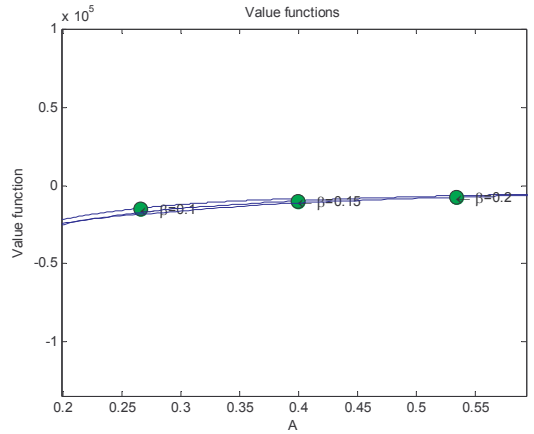

Effect of $\beta$ (zoomed) 